\title{
WestVirginiaUniversity
}

THE RESEARCH REPOSITORY @ WVU

Graduate Theses, Dissertations, and Problem Reports

2020

\section{Topics in Cultural and Entertainment Economics}

Justin W. Parker

jwp0005@mix.wvu.edu

Follow this and additional works at: https://researchrepository.wvu.edu/etd

Part of the Public Economics Commons, and the Regional Economics Commons

\section{Recommended Citation}

Parker, Justin W., "Topics in Cultural and Entertainment Economics" (2020). Graduate Theses,

Dissertations, and Problem Reports. 7506.

https://researchrepository.wvu.edu/etd/7506

This Dissertation is protected by copyright and/or related rights. It has been brought to you by the The Research Repository @ WVU with permission from the rights-holder(s). You are free to use this Dissertation in any way that is permitted by the copyright and related rights legislation that applies to your use. For other uses you must obtain permission from the rights-holder(s) directly, unless additional rights are indicated by a Creative Commons license in the record and/ or on the work itself. This Dissertation has been accepted for inclusion in WVU Graduate Theses, Dissertations, and Problem Reports collection by an authorized administrator of The Research Repository @ WVU.

For more information, please contact researchrepository@mail.wvu.edu. 


\title{
Topics in Cultural and Entertainment Economics
}

\author{
Justin W. Parker
}

Dissertation submitted to the John Chambers

College of Business and Economics at

West Virginia University in partial fulfillment of the of the requirements for the degree of Doctor of Philosophy in Economics

\author{
Joshua Hall, Ph.D., Chair \\ Bryan McCannon, Ph.D. \\ John Deskins, Ph.D. \\ John Dove, Ph.D. \\ Department of Economics
}

\author{
Morgantown, West Virginia \\ 2020
}

Keywords: Entertainment, hedonic, cultural economics, survival analysis, hotel demand

Copyright 2020 Justin W. Parker 


\title{
ABSTRACT \\ Survival of the Fittest: An Analysis of Network Television Show \\ Competition, 1978-1993
}

\author{
Justin W. Parker
}

During the first 60 years of television broadcasting, prime time programming was dominated by the "Big Three" networks-NBC, ABC, and CBS. Their dominance in the market functioned as an oligopoly, supported by longstanding regulatory structures. Beginning in the 1970s, a wave of deregulation and change from satellite technology swept the industry, making it easier for other firms to enter the market. In 1986, the premiere of FOX saw a viable fourth network break through to compete with the Big Three. This paper analyzes inefficiencies on both the cost and content production side of prime time television, using survival analysis to study both the practices of Big Three networks with respect to programming as well as potential gaps in Big Three coverage which were exploitable by FOX to gain a foothold, finding in particular that FOX's observed practice of stacking comedies on Sundays took place at the same time that Big Three networks were facing weakness on Sundays in terms of show survival.

JEL Codes: Z10, K20, L82

Keywords: television economics, network television, survival analysis, regulation 


\title{
ABSTRACT \\ Blackjack or Bust: The Effect of New, Local Casino Construction on Housing Transaction Prices in Franklin County, OH
}

\author{
Justin W. Parker
}

In recent years, city governments across the U.S. have sought to address the problems of industrial decline and urban blight through initiatives designed to revitalize local areas and fill the empty coffers of municipal and state governments. One popular option in this quest has been a push for the legalization of gambling coupled with the construction of new casinos and other gambling facilities; of which the Hollywood Casino in Franklin County, OH (opened in 2012) is a good example. This paper uses several hedonic methods-including the standard hedonic model, a repeat-sales (RSR) model, and a hybrid model in the manner of Case and Quigley (1991)-to explore the effect of this new casino on property values. All methods find evidence of a negative effect on housing values associated with proximity to the casino, implying that at least with respect to individual plot values the addition of the casino is in fact a disamenity to residents. The final component of this paper seeks to measure whether the losses in property tax revenue associated with this decline in value meet or exceed the revenue stream generated from casino activities; finding evidence in favor of property tax tradeoffs in excess of casino revenues to the local government.

JEL Codes: H71, L83, R31

Key Words: casino, hedonic, real estate, property taxes, local government 


\title{
ABSTRACT \\ Why Go Home? The Impact of Pearl Jam's "Home Shows" on Hotel Demand
}

\author{
Justin W. Parker
}

We use daily hotel data on price, occupancy, and revenue to analyze the economic impact of Pearl Jam's "Home Shows" in Seattle, WA. These two concerts were attended by over 100,000 Pearl Jam fans, many from outside the state of Washington, including international tourists. We find that the Home Shows generated approximately 230,000 hotel nights before, during, and after the two concerts. With an increase in the average daily room rate ranging from $\$ 12$ six days prior to $\$ 144$ on concert days, hotel revenue in Seattle increased by over $\$ 58$ million as a result of the Home Shows. We estimate that increased demand from Pearl Jam fans led to an increase in hotel tax revenue of between $\$ 6.69$ million and $\$ 9.15$ million. While the 'Home Shows' received no direct public subsidy, we argue that our results represent a 'best case' scenario on the public revenue side of large cultural events that attract tourists.

JEL Codes: I20, I23, L33, L38

Key Words: Pearl Jam, hotel nights, destination events, 


\section{Contents}

1 Survival of the Fittest: An Analysis of Network Television Show Competition, 1978-1993 1

1.1 The Development of Network Television, and Television Show Production 3

1.1.1 The Rise and fall of "the Big Three" Oligopoly . . . . . . . . 4

1.1.2 The Production Process for a Network Television

Series .......................... 9

1.2 The Demand for Television Shows . . . . . . . . . . . . . . . . 10

1.3 Theoretical Model . . . . . . . . . . . . . . . . . . . . . . . . . . 12

1.4 Data and Empirical Approach . . . . . . . . . . . . . . . . . 14

1.5 Empirical Results . . . . . . . . . . . . . . . . . . . . . 20

1.5.1 Survival Analysis . . . . . . . . . . . . . . . 20 20

1.5.2 Analysis of Survival Curves . . . . . . . . . . . . . 22

1.6 Conclusion . . . . . . . . . . . . . . . . . . . . . . . . . . . . . . 23

2 Blackjack or Bust: The Effect of New, Local Casino Construction on Housing Transaction Prices in Franklin County, OH 25

2.1 Introduction . . . . . . . . . . . . . . . . . . 25

2.2 Literature Review . . . . . . . . . . . . . . . . . . . . . . . . . . . . . . . 29

2.3 Methods and Data . . . . . . . . . . . . . . . 35

2.3.1 Franklin County, OH Real Estate Data . . . . . . . . . . . . 35

2.3.2 Empirical Methods . . . . . . . . . . . . . . . . . . . 41

2.4 Regression Results . . . . . . . . . . . . . . . . . . . 46

2.4 .1 Hedonic Results . . . . . . . . . . . . . . . . . 46

2.4.2 RSR and Hybrid Model Results . . . . . . . . . . . . . . 48

2.5 Implications for Local Public Finance . . . . . . . . . . . . . . 50

2.6 Conclusion . . . . . . . . . . . . . . . . . . . 54

3 Why Go Home? The Impact of Pearl Jam's "Home Shows" on Hotel Demand 56

3.1 Data and Methods . . . . . . . . . . . . . . . . . 59

3.2 Empirical Results . . . . . . . . . . . . . . . . . . . . . . . . 62

3.3 Robustness Check . . . . . . . . . . . . . . . . . . . . 65 
3.4 Conclusion . . . . . . . . . . . . . . . . . . 67

$\begin{array}{lr}\text { Bibliography } & 69\end{array}$

$\begin{array}{ll}\text { Appendix } & 77\end{array}$ 


\section{List of Figures}

1.1 Primetime Comedy Shows by Day of Week Aired in First Season, 1983$1993 \ldots \ldots \ldots \ldots \ldots \ldots$

1.2 Primetime Comedy Shows by Day of Week Aired in Second Season,

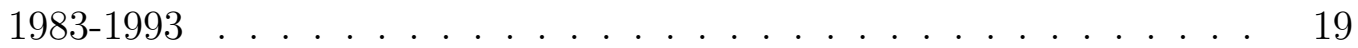

2.1 Total Crimes and Casino-Specific Crimes in Franklin County, OH 2013$2017 \ldots \ldots \ldots \ldots \ldots \ldots \ldots$

2.2 Location of Single Family Homes Transacted from 2001-2012 on Platted Lots within 6 Miles of Hollywood Casino Columbus . . . . . . . . 36

2.3 Price Gradient, Combined Sample within 6 Miles of Hollywood Casino 38

2.4 Logged Price Differentials Index, 2001-Present . . . . . . . . . . . . 40

3.1 Average ADR by Weekday, 2004-2018 vs. Week of Home Shows . . . 61

3.2 Average ADR by Weekday, Aug. 2004-2018 vs. Week of Home Shows 62

3.3 Model 1 Kaplan-Meyer Survival Curve, NBC . . . . . . . . . . . . . . 77

3.4 Model 2 Kaplan-Meyer Survival Curve, NBC . . . . . . . . . . . . . . 78

3.5 Model 3 Kaplan-Meyer Survival Curve, ABC . . . . . . . . . . . . . . 78

3.6 Model 4 Kaplan-Meyer Survival Curve, ABC . . . . . . . . . . . . . . 79

3.7 Model 5 Kaplan-Meyer Survival Curve, CBS . . . . . . . . . . . . . . 79

3.8 Model 6 Kaplan-Meyer Survival Curve, CBS . . . . . . . . . . . . . . 80 


\section{List of Tables}

1.1 Summary of Prime Time TV Shows in Season One by Day, 1983-1993 15

1.2 Summary of Prime Time TV Shows in Season One by Genre, 1983-1993 15

1.3 Summary of Prime Time TV Shows in Season Two by Day, 1983-1993 16

1.4 Summary of Primetime TV Shows in Season Two by Genre, 1983-1993 17

1.5 Survival Analysis (Cox Proportional Hazards) Results . . . . . . . . . 21

2.1 Summary Statistics . . . . . . . . . . . . . . . . . . . . . . . . . . . . . . . . . .

2.2 Mixed Model Results . . . . . . . . . . . . . . . . . . . . . . . . . 44

2.3 Hedonic Results-Single Transaction Sample . . . . . . . . . . . . . . 47

2.4 Hedonic Models-Combined Sample . . . . . . . . . . . . . . . . . 48

2.5 RSR and Hybrid Models . . . . . . . . . . . . . . . . . . . . . . 49

2.6 Local Disbursements by Line Item and Year . . . . . . . . . . . . . . 52

2.7 Casino Tax Revenue vs. Foregone Property Tax Revenue . . . . . . . 53

3.1 Summary Statistics . . . . . . . . . . . . . . . . . . 60

3.2 Econometric Models . . . . . . . . . . . . . . . . . . . 64

3.3 Placebo Models . . . . . . . . . . . . . . . . . 66 


\section{Chapter 1}

\section{Survival of the Fittest: An Analysis of Network Television Show Competition, 1978-1993}

\section{I: Introduction}

"When you're young, you look at television and think, there's a conspiracy. The networks have conspired to dumb us down. But when you get a little older, you realize that's not true. The networks are in business to give people exactly what they want." -Steve Jobs

Source: The Wall Street Journal

The above quote from legendary tech tycoon Steve Jobs rightly describes the network television market as being driven by the same economic forces of supply and demand as others. Jobs' quote focuses on demand for certain types of television shows as the driving force behind what television networks decide to put on air. Indeed, the entire system of television show production, renewal, and cancellation can be viewed as a dynamic process by which networks discover and respond to the desires of television viewers. Given the lack of perfect a priori information regarding such preferences, 
this process is often chaotic: the vast majority of television shows are cancelled after the first season. A handful of shows survive for a few more seasons, and a select few television shows manage to last much longer; such shows (as for example CBS's Murphy Brown) can even shape national political and cultural discourse.

Television show survival depends on many factors, but perhaps the most important is the system of television ratings produced by the Nielsen Company. Such ratings are directly connected to the price of television advertising, which is in turn directly connected to the total revenue taken in by a network. To elaborate, McNair (2017) estimates that traditional TV advertising brought in $\$ 71.65$ billion, or a third of total media advertising spending, in 2017. Advertising dollars are fought over by both the major networks as well as smaller channels, who negotiate higher ad buys based upon viewership. The number of networks competing for said dollars is clearly an important consideration, as are the various factors which determine the success of particular television shows.

During the first 60 years of broadcast television, the market was dominated by three networks-CBS, NBC, and ABC-known as the "Big Three." Their oligopical dominance was dependent in large part on technological and regulatory factors which remained static from the 1920s until the late 1970s and early 1980s. Another major contributing factor were the creative partnerships between studios and networks which served as a pipeline for major talent to be channeled into Big Three television shows. A final factor was the difficulty presented by scheduling and genre; directly competing with the Big Three involved running shows during prime days for television viewing by audiences-the networks often stacked certain nights of the week with their best television shows, with one prominent example being NBC's Thursday night lineup in the 1980s, in which they stacked popular shows like The Cosby Show,A Different World, and Cheers back-to-back, with shows on other networks rarely rising to the 
level of direct competition.

This system would face threats on multiple fronts following a series of regulatory and technological changes during the late 1970s. The first threat to arise was the emergence of cable television, which offered an alternative to traditional broadcast networks via satellite technology. However, the biggest change to primetime network television would be the rise of the fourth network, FOX, in 1986.

This paper will seek firstly to provide an exposition into the evolution of the technological and regulatory structure which allowed the Big Three to dominate, as well as the changes which allowed FOX to enter the market and succeed where others had failed, with a discussion of the relevant theory on oligopical industrial organization. This will essentially cover the first two of three aforementioned reasons for oligopoly in network television during the mid-20th century. The empirical second portion will center on the third reason, and will attempt to analyze inefficiencies present under the Big Three primetime television scheduling regime in order to gain insight into how FOX found fertile soil to develop an audience.

\subsection{The Development of Network Television, and Television Show Production}

This section seeks to describe the process of television show inception and production in detail, looking at the historical development of network television as well as the production process. 


\subsubsection{The Rise and fall of "the Big Three" Oligopoly}

The story of television up until the 1970s was one of a few concentrated, original content-producing networks. In the early years, the Big Three-NBC, ABC, and CBS - competed against each other and the DuMont network. In 1956, DuMont ceased operations due in large part to an inability to compete with the number of stations boasted by other networks (Weinstein, 2006). This left U.S. media markets with only three network providers of original content. Given the early role that the Big Three played in the development of communications technology and infrastructure across the country, they possessed vast market share which gained protection from the government early on in the form of regulations.

Said regulations came about quite interestingly as a result of an effort on the part of the Federal Communications Commission (FCC) to promote competition in media markets. Due to the early technological edge elaborated on in the previous section, NBC found itself with a large national network of television stations. Indeed, some cities even had two NBC stations, such as New York, Chicago, and Washington, D.C. (FCC Network Inquiry Special Staff, 1980). If the trajectory at the time had continued, it was possible for NBC to form a monopoly over television communications in much the same way AT\&T formed a monopoly over telephone communications (albeit the AT\&T monopoly was specifically allowed for by government provision). With this in mind, the FCC decided to limit the number of stations that individual networks could operate in one city's media market. These regulations, known as chain broadcasting rules, helped to bring NBC to heel, and promote the rise of other extant networks into fuller competition (FCC Network Inquiry Special Staff, 1980).

However, one must question the actual effects of the chain broadcasting regulations. While it was now possible for the other, established networks to compete 
within individual media markets, it was next to impossible for a network to arise and compete with the major players and all of their affiliates in said local media markets, both nationally and individually, due to the economies of scale enjoyed by the large networks. In order to form a company which could compete directly with the Big Three, one would need a massive amount of capital to invest in a large number of stations and infrastructure in different media markets, while also building a national infrastructure to broadcast content. Only with these things, as well as a large pool of creative talent, could a new network hope to compete with the existing advantages of the networks. Thus, several barriers to entry existed which kept the Big Three firmly ensconced as the sole providers of primetime television content well into the late 20th century. For more information on economies of scale in network broadcasting, refer to Litman (1979). Another issue with the FCC's ruling was a lack of willingness to actually enforce the rules against major networks in many cases, resulting in even further challenges for smaller competitors relative to the Big Three (Anonymous, 1951). Television would remain essentially unchanged until the 1970s.

While the chain broadcasting rules were important, another series of regulations would help solidify a network oligopoly by the Big Three. In 1952, the FCC issued the Sixth Order and Report (41 FCC 148, 1952). According to Thomas and Litman (1991) this new policy effectively restricted the number of very high-frequency (VHF), over the air commercial television stations receivable by markets across the country. Specifically, the FCC limited the number of channels in each media market to a quantity between one and nine depending on the size of the market; this, coupled with requirements by the FCC regarding channel separation would effectively limit the number of VHF receivable channels in the 100 largest media markets to three. In theory, the commission allowed for competition over ultra-high frequency (UHF) broadcast via conventional means at the time, but then-significant technological bar- 
riers prevented a viable competitor due to the lower quality of UHF broadcasts over extant infrastructure.

The final pieces of the regulatory puzzle are the Financial Interest and Syndication rules, which barred broadcasting companies from actually owning the content that they produced. This meant that each network had to have an independently-owned syndication provider to distribute original, prime time content. It also meant that the ability of networks to profit off of the syndication licensing of their shows was limited (Besen, 1986).

Several factors would converge to finally end the dominance of primetime television by the Big Three. The first was related to the development of satellite technology. During the 1950s and 1960s, a massive amount of public spending was directed towards the advancement of space exploration technology. In 1962, the first American satellite, Telstar, was placed into orbit (US Space Objects Registry, 2013). In the year following this successful launch, the first geostationary orbital satellite was launched, Syncom II. Geostationary satellite technology offered a chance to constantly beam content from a single satellite across a certain geographic area by keeping pace with the Earth's rotation (Bray, 1965). This allowed for faster and better quality transmissions of content, and the national, terrestrial networks of the Big Three quickly became obsolete. A window opened which provided a cheaper option to stream content versus these old systems. This change would give birth to cable and satellite television during the 1970s, systems which challenged the old networks by introducing new channels with different content than that which was carried by the major networks-this paper refers to Parsons (2008) regarding cable television history. In 1972, the FCC determined that the development of better satellite technology necessitated a policy which opened up licensure for satellite operations to many firms - this policy became known as the "Open Skies" rule (Federal Communications Commission, 
1972). Understandably, the removal of government licensure burdens from potential operators allowed for the entry of new networks, bringing an injection of competition into the television market. Upon an inspection of the content being produced at the time - unconventional sports on ESPN, Christian programming on CBN-it is clear that the new cable stations were not attempting to compete directly with the primetime products of the Big Three. However, certain programming such as news (CNN) and movie broadcasts (HBO) were indeed challenged by early cable programming, reducing the market share of Big Three networks (The Cable Center, 2015). Direct competition with primetime programming on cable networks wouldn't come until the mid to late 1990s.

However, in the late 1980s with the launch of FOX by Rupert Murdoch, the CEO of 20th Century Fox, a new competitor arose to challenge the status quo. Upon its premiere in October of 1986, FOX appeared on 99 TV stations, reaching more than $80 \%$ of U.S. homes (Thomas \& Litman, 1991). This number increased to 108 affiliates in early 1987 (Anonymous, 1987), and 115 by the end of that year (Mahoney, 1987), giving FOX an 86\% reach. The question lingers: why did FOX succeed where many other previous attempts had failed? The answer lies primarily with a change in regulatory structure which allowed FOX to take advantage of the same technology which contributed to the rise of cable television. In 1980, the FCC undertook a thorough study of network industrial organization, which led to several later policies intended to increase competitiveness. The first was a 1980 decision which eliminated cable distant signal importation rules, which made it even easier to stream content across long distances, complementing the earlier "open skies" decision. The conjunction of "open skies" with the new policy allowed for competition via UHF frequencies, as the difference in quality was indiscernible over cable broadcasts. The second was the 1985 increase in multiple station ownership from 7 to 12 stations, a continuation of a 
then-ongoing breakdown in the chain broadcasting rules of 1941 (Thomas \& Litman, 1991). Both of these developments allowed for an increase in UHF local stations, which built a base upon which FOX could negotiate affiliate agreements. Finally, FOX was able to take advantage of the regulatory environment at the time by programming just under the number of hours required by the FCC to be considered a network. This allowed FOX to skirt the aforementioned Financial Interest and Syndication Rules, which in turn allowed for further network revenue from syndication of original programming (Heldenfels, 1994).

Thus, FOX found fertile soil for a fourth network, and took full advantage of the opportunity presented. A final important factor which influenced FOX's rise aside from the regulatory environment was the increase and shift in tastes and preferences of demand for programming across households, and FOX's unique position to provide new, quality programming. Crandall (1974) makes the case for a fourth network in part by arguing that demand for new programming would continue to increase as Americans spent more and more time watching television, even on the weekends. Indeed, by 1985 average television viewing hours per day had risen to an all-time high of 7 hours and 10 minutes (Broadcasting Publications, 1987). These developments undercut long-help beliefs in demand for television across the different day/genre combinations, and contributed to an increase in demand for new programming that FOX was all too happy to exploit. FOX would find its earliest success with The Simpsons, a cartoon comedy featuring the eponymous family's hijinks. Indeed, for the years in this paper's data, The Simpsons are the only FOX program to break into the top 30 television shows, as rated by Nielsen. FOX was able to provide programs such as The Simpsons and Beverly Hills, 90210 due to existing connections with 20th Century Fox and other production companies. This allowed FOX access to pools of highly sought-after creative talent, which increased the quality of their programs and 
attracted new viewers.

\subsubsection{The Production Process for a Network Television Series}

To conclude this section, I will provide a brief explanation of how a network television series is developed and put on the air:

Firstly, a writer has to produce a concept and pilot for a new series. This process involves a large number of writers competing with one another for an extremely limited number of new TV slots. The writer will then take his concept to a network client-linked production house (in our sample, the clients are ABC, NBC, CBS and FOX; each client has a production house linked to it), or to a major film studio such as Universal, Paramount, or Disney. In the production of prime time television, these production companies have the deepest pockets and the largest pool of talent and collective industry "know-how" and relationships; thus, television shows produced by said large companies have a clear advantage over those produced by so-called independent studios, which are few and far in between. In order to get a show on air, the concept, the story, the script, and the cast have to be approved by the studio where the show will be filmed, the network on which it will be broadcast, and the show's production company. Most shows are brand-new concepts; a few shows are spinoffs of existing series, and often have an easier time in the production process.

Once all of these boxes are checked, the production process will move on to shooting a pilot episode. Pilots are often two-hour long episodes meant to spur interest in the show. If a pilot proves successful, the network will order a short series of 4-6 episodes. If it sees continued success, the network will order more; a full season is 22 episodes. Networks decide on day and time slots based upon an a priori estimation of 
how successful a show will be in said time slot given its various attributes alongside the performance of previous similar television shows.

\subsection{The Demand for Television Shows}

Demand for television shows is based on a variety of determinants in much the same way as other products depend on the same. In the previous section, an increase in both the number of households as well as the average number of hours spent watching television were discussed as factors increasing overall demand. In this section, I will discuss the factors influencing consumer preference for one T.V. show versus another. This section will be important for the empirical model to be discussed in following sections.

An all-important consideration in determining consumer preferences for different programs is based around the day of the week in question. Weekend prime time generally starts earlier in the evening, at 7PM, because most people are home all day. Hour-long T.V. dramas are generally scheduled for weekend and late-night slots as well, which is understandable if one considers that people likely crave quick, simple, entertaining programming immediately following the work day. Weekend shows also tend to be less popular than weekday shows because more people are out of the house during the weekends and Friday evening; one prominent exception would be Sunday evenings, when most people are at home preparing for the coming work week. Different days of the week tend to be more popular for T.V. shows as well; in this paper's sample, Tuesday, Wednesday, and Thursday tend to boast most of the top ten programs. Clearly, the days of the week as well as the different times of day that programs air influence the demand for said programs, and networks place programs in said time slots accordingly. This creates an endogeneity problem when considering 
demand for T.V. shows, as networks are actively placing shows in slots where they receive maximum potential.

Another factor which could influence the demand for T.V. shows, and is dependent on time-specific factors, is whether or not a show precedes or follows another popular show. This is easy to understand-people could flip to a channel early to catch a popular show, or fail to change the channel once said show has concluded. Again, networks place shows before or after hits in order to maximize potential, creating endogeneity issues when considering this factor.

Finally, content considerations are important to T.V. show demand as well. The earlier discussion of T.V. show production companies is important, as they generally produce better-quality television shows based on available technology and acting talent. While the names of each company have varied over the years, said major production companies include, or have included: ABC Television, CBS Television, NBC Television, TriStar Television, 20th Century FOX Television, Universal Television, Columbia Television, Walt Disney Television, Touchstone Television, Paramount Television, Warner Bros. Television, MGM Television, and Viacom Television. Genre is also important under the content umbrella - sitcoms tend to be incredibly popular, and the desire for entertainment over plot and substance was a noted development during the years in this paper's sample. (Smith, 1985). The presence of notable actors and actresses on screen can also influence demand for (and production of) T.V. shows - Burt Reynolds, for instance, was able to leverage his fame on the silver screen into a popular T.V. drama, Evening Shade. 


\subsection{Theoretical Model}

According to Varian (2009), three popular theoretical models exist to explain oligopical competition in the marketplace based around either quantity (Cournot) or price (Bertrand) competition. This means that under each framework, companies seek to set either quantity or prices in response to the actions of other companies. This section can be thought of as an attempt to organize the narrative presented previously into economic terms. The main source of revenue from prime time television comes from advertising revenue. This can be considered the revenue per unit of television consumed for network $i \in[1, I]$ defined as $\alpha_{i}$, or more specifically in this case the unit of revenue per each viewer via Nielsen ratings. Meanwhile, since television is largely nonexcludable for prime time network programming, there is no price rationing mechanism in place. The "prices" that firms choose to pass on to the consumer, the control variable considered here, must be put in different terms. Costs borne by the consumer include both the proportion of advertising time, which is assumed a universal disutility to consumers, and the cost in terms of a show being far off from their preferences.

The former will be considered first. The price of advertising per slot is clearly endogenous to this model: the greater the demand for television shows $D$, the greater the demand for advertising and thus the higher the price per slot. The proportion of advertising per unit television consumption is also relevant to the price of advertising as well as television demand; this model will assume that demand is essentially inelastic relative to advertising proportion over the range of values for the vector of advertising proportions per show $p_{i}$ that networks are willing to consider, meaning that $\frac{\partial D}{\partial p_{i}}=0$. Thus, advertising markets are taken as exogenous, and the price of advertising $\alpha_{i}$ is taken as a parameter, as well as the proportion of advertising $p_{i}$.

As for the latter cost, define a vector $\theta_{C}$ which represents a set of television 
consumer preferences; values for this vector are greater than zero. A second vector, $\theta_{i}^{e}$, defines the expectations of network $i \in[1, I]$ with respect to the beliefs and preferences of consumers. These beliefs on the part of the network express themselves in the qualities each show has, both those which cost money to produce (set quality, etc.) as well as genre (ex. comedy). Taking this into account, consider

$$
\theta_{i}^{e}-\theta_{C}=\eta
$$

where $\eta$ measures the difference between network beliefs about preferences and consumer beliefs. A goal of any network is to minimize this value as much as possible given the cost environment; $\frac{\partial D}{\partial \eta}<0$. Networks are assumed to be profit-maximizing agents who face the optimization problem

$$
\underset{\eta, p_{i}}{\operatorname{Max}} \pi_{i}=R(\eta)-C(\eta)=\alpha_{i} D\left(\theta_{i}^{e}\right)-C\left(\theta_{i}^{e}\right)
$$

Ultimately, revenue is dependent on demand, which is dependent on $\eta$ and thus the firm's choice variable $\theta_{i}^{e}$. Costs can be thought of as a function of $\theta_{i}^{e}$ primarily because the network bears costs to produce the set of qualities present in a television show.

The above formulation offers unique insights into the market for network television around the time that FOX entered the market. Firstly, while networks optimized $\eta$ to try and come as close to true beliefs as possible, ultimately there would always be a margin of error. The main issue would be a systemic misestimation of consumer preference which was recurrent across time. This is the kind of inefficiency FOX could use to an advantage.

On a larger scale, this model is also helpful to link back to the discussion about how the oligopoly was built in the first place. The cost function is key-nearly every 
single line item discussed in the earlier narrative had the effect of raising the minimum costs of maintaining a competative network across the country. With the regulatory hurdles overcome, and with the resources of 20th Century FOX to ensure a factory for quality programming, FOX was well on its way to flattening the advantage enjoyed by the Big Three networks in their cost structure. This allowed FOX to focus more resources on finding underutilized times and genres in the primetime lineup of the time.

\subsection{Data and Empirical Approach}

Alongside theoretical analysis of the effect that FOX's entry had on Big Three viewership in the prior section, I will also analyze various factors that could influence demand for Big Three programming, and thus a show's survival, using a survival analysis framework. This approach is inspired by De Vany (2008), which studies motion picture survival in theaters. It adds greater dimension to the data by testing whether or not there is statistical evidence of covariate effects on survival. Much in the same way, it gives deeper insight into timely market performance in prime time television, highlighting under which genres and days of the week Big Three television shows tended to struggle. Understanding this is key to understanding how FOX utilized areas of inefficiency in programming to gain an audience foothold. I will assume that network executives make decisions on television show cancellation and renewal based upon current and expected viewership. Thus, television show survival depends

on the demand for each television show, which in turn depends on several factors such as those discussed previously.

The data for this section of my empirical analysis comes from Brooks and Marsh (1999), and includes all Fall primetime television shows which premiered on the Big 
Three networks as well as FOX from 1983 to 1993. The summary statistics are reported as television show counts of each category under a specific network. The proportions for each category as a portion of total network shows is also reported. Two tables are reported for both day of week and genre: one for the first season, and another for the second season. In this way, insight is gained into differences between shows that survive the first season versus the total sample.

Table 1.1: Summary of Prime Time TV Shows in Season One by Day, 1983-1993

\begin{tabular}{rcccccccc}
\hline Day & ABC & Proportion & CBS & Proportion & NBC & Proportion & FOX & Proportion \\
\hline Sunday & 10 & 0.128 & 1 & 0.013 & 12 & 0.167 & 16 & 0.533 \\
Monday & 1 & 0.013 & 16 & 0.205 & 4 & 0.056 & 1 & 0.033 \\
Tuesday & 14 & 0.179 & 6 & 0.077 & 9 & 0.125 & - & - \\
Wednesday & 15 & 0.192 & 22 & 0.282 & 8 & 0.111 & - & - \\
Thursday & 9 & 0.115 & 9 & 0.115 & 5 & 0.069 & 6 & 0.200 \\
Friday & 14 & 0.179 & 12 & 0.154 & 16 & 0.222 & 4 & 0.133 \\
Saturday & 15 & 0.192 & 12 & 0.154 & 18 & 0.250 & 3 & 0.100 \\
\hline Total & $\mathbf{7 8}$ & & $\mathbf{7 8}$ & $\mathbf{7 2}$ & \multicolumn{3}{|c}{$\mathbf{3 0}$} \\
\hline
\end{tabular}

Note: Proportion shows share of network total, or the count divided by the column total for the network.

Across all Big Three networks, the number of shows released in the first season, and the number of shows which survive to the second season, is remarkably equal, with NBC releasing slightly fewer new shows. FOX of course is far behind the Big Three, with about half their numbers. This makes sense, given that FOX was only extant for the latter half of the time period the data comes from, and only really competed in prime time beginning in 1987.

Table 1.2: Summary of Prime Time TV Shows in Season One by Genre, 1983-1993

\begin{tabular}{rcccccccc}
\hline Genre & ABC & Proportion & CBS & Proportion & NBC & Proportion & FOX & Proportion \\
\hline Action/Adventure & 5 & 0.064 & 4 & 0.051 & 4 & 0.056 & - & - \\
Comedy & 42 & 0.538 & 38 & 0.487 & 41 & 0.569 & 21 & 0.700 \\
Documentary & - & - & 2 & 0.026 & - & - & 1 & 0.033 \\
Drama & 17 & 0.218 & 16 & 0.205 & 10 & 0.139 & 2 & 0.067 \\
Other & 3 & 0.115 & 14 & 0.179 & 12 & 0.167 & 2 & 0.067 \\
Legal/Police Drama & 0.038 & - & - & 1 & 0.014 & 1 & 0.033 \\
Science Fiction/Fantasy & 1 & 0.013 & 2 & 0.026 & 4 & 0.056 & 2 & 0.067 \\
Western & 1 & 0.013 & 2 & 0.026 & - & - & 1 & 0.033 \\
\hline Total & $\mathbf{7 8}$ & & $\mathbf{7 8}$ & & $\mathbf{7 2}$ & & $\mathbf{3 0}$ \\
\hline
\end{tabular}

Note: Proportion shows share of network total, or the count divided by the column total for the network. 
Some days of the week seem to have been more popular for certain networks to premiere new shows. In Table 1.1, ABC's new shows are distributed relatively evenly across all days of the week save for Monday. CBS is wary of Sundays and Tuesdays, while favoring Monday and Wednesday. NBC tends to favor Friday and Saturday relative to other days of the week for new show premieres. Finally, FOX made the decision to only attempt to compete with other networks on certain days during the early stages of the company. Thus, they have no shows which show on Tuesday or Wednesday, and they are heavily favorable to competing on Sundays.

Table 1.3: Summary of Prime Time TV Shows in Season Two by Day, 1983-1993

\begin{tabular}{rcccccccc}
\hline Day & ABC & Proportion & CBS & Proportion & NBC & Proportion & FOX & Proportion \\
\hline Sunday & 3 & 0.125 & 1 & 0.045 & 2 & 0.083 & 4 & 0.571 \\
Monday & 3 & 0.125 & 6 & 0.273 & 2 & 0.083 & - & - \\
Tuesday & 3 & 0.125 & 3 & 0.136 & 5 & 0.208 & - & - \\
Wednesday & 6 & 0.250 & 4 & 0.182 & 1 & 0.042 & - & - \\
Thursday & 2 & 0.083 & 2 & 0.091 & 5 & 0.208 & 1 & 0.143 \\
Friday & 4 & 0.167 & 3 & 0.136 & 2 & 0.083 & - & - \\
Saturday & 3 & 0.125 & 3 & 0.136 & 7 & 0.292 & 2 & 0.286 \\
\hline Total & $\mathbf{2 4}$ & $\mathbf{2 2}$ & $\mathbf{2 4}$ & $\mathbf{7}$ \\
\hline
\end{tabular}

Meanwhile, the distribution of shows surviving to season two across days of the week in their second season in Table 1.3 deserves mention. ABC is again relatively evenly distributed, save for Thursday. CBS also has fewer shows on Thursday survive to the second season; however NBC has a number of shows-primarily The Cosby Show and A Different World-which lasted many seasons and were shown back to back on Thursday evenings. Other strong days for NBC were Tuesday and Saturday, while CBS tended to favor Monday heavily. Finally, FOX heavily favored Sunday for second season renewal, alongside Saturday and Thursday.

Tables 1.2 and 1.4 are similar to the other summary tables, but different in that they include the same information across several general bins for Genre. Many of them are relatively straightforward. Documentaries include traditional documentaries as 
Table 1.4: Summary of Primetime TV Shows in Season Two by Genre, 1983-1993

\begin{tabular}{rcccccccc}
\hline Genre & ABC & Proportion & CBS & Proportion & NBC & Proportion & FOX & Proportion \\
\hline Action/Adventure & 2 & 0.083 & 10 & 0.455 & - & - & - & - \\
Comedy & 15 & 0.625 & 2 & 0.091 & 13 & 0.542 & 6 & 0.857 \\
Drama & 2 & 0.083 & 4 & 0.182 & 3 & 0.125 & 1 & 0.143 \\
Legal/Police Drama & 4 & 0.167 & 4 & 0.182 & 7 & 0.292 & - & - \\
Science Fiction/Fantasy & - & - & 1 & 0.045 & 1 & 0.042 & - & - \\
Western & 1 & 0.042 & 1 & 0.045 & - & - & - & - \\
\hline Total & $\mathbf{2 4}$ & & $\mathbf{2 2}$ & & $\mathbf{2 4}$ & & $\mathbf{7}$ & \\
\hline
\end{tabular}

Note: Proportion shows share of network total, or the count divided by the column total for the network.

well as docuseries and cop documentaries such as Rescue 911. Legal/Police Dramas cover anything that is, put simply, of a non-comedic nature and related to law enforcement in the field as well as in the courtroom. "Other," finally, is a basket that contains shows which have no place in any of the other categories. The count is quite small, so this genre isn't of particular focus to this analysis.

Comedies, which include sitcoms, are the dominant genre across all networks in Table 1.2, making up about half of shows premiered in every case. Dramas and Legal/Police Dramas rounded out the top three genres, with other categories making up the rest. In Table 1.4, one can see that no shows from the category "Other" were ever renewed for a second season. Proportions in each network and across most categories matched relatively closely with the proportion of shows premiered in Table 1.2.

One exception is worthy of note: FOX. Of all shows renewed by FOX, $86 \%$ of them were comedies. Of the shows renewed, $57 \%$ of them were also on Sundays. The intersect of the two is also, incidentally, $57 \%$, meaning that $57 \%$ of shows renewed for a second season were comedies on Sundays. Compared to similar statistics for other networks, this likely represents a play for Sunday viewership through comedies. Going back to our model of oligopoly in the previous section, this is an example of FOX trying to gain a competitive foothold against the Big Three by offering different programming on Sundays.Figures 1.1 and 1.2 provide insight into this; of all comedy 
Figure 1.1: Primetime Comedy Shows by Day of Week Aired in First Season, 1983-1993

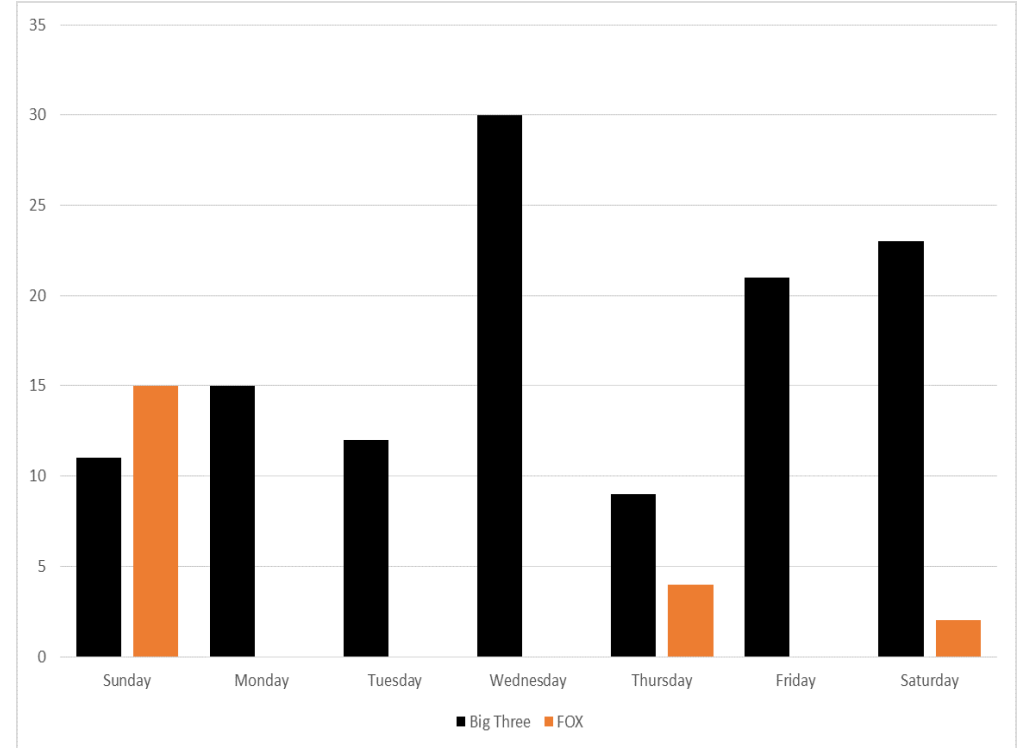

shows premiered (Figure 1.1) and were renewed for a second season (Figure 1.2), FOX takes a large position on Sundays.

In another manner of speaking, survival analysis allows us to study whether or not certain covariates affect the hazard function for television show survival. A hazard function can be thought of as the probability of failure at a specific point in time given that the subject has survived up until time $t$ or later. This function can be defined as

$$
h\left(t_{j}\right)=h_{0}(t) e^{\beta X_{t}}
$$

where $t$ is the observed time for subject $j$ and $X_{j}$ is a vector of covariates. The function $h_{0}(t)$ is important with respect to assumed form; for this analysis I will use two different methods of treating this function. The model chosen for use is the Cox Proportional Hazards model, which was introduced by D. R. Cox (1972), and is distinct from other conventional proportional hazards model in that it assumes no parametric form for the function $h_{0}(t)$. In this respect, the paucity of assumptions 
Figure 1.2: Primetime Comedy Shows by Day of Week Aired in Second Season, 1983-1993

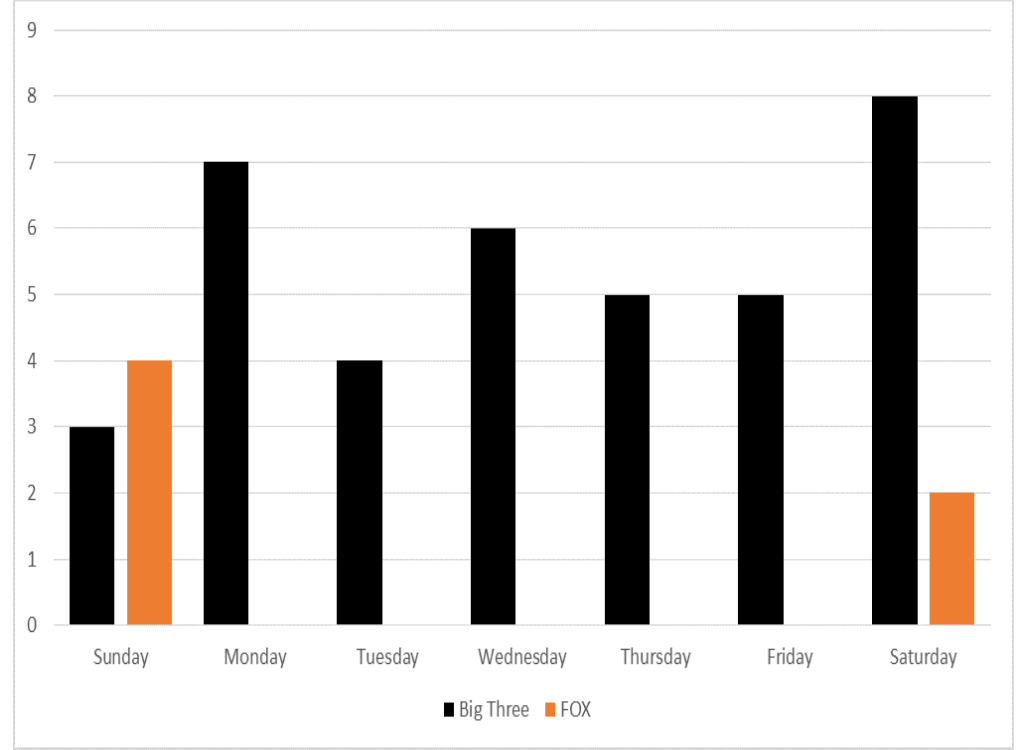

renders the Cox model preferable for this analysis. A primary assumption of proportional hazards models is that the effect of the increase in the hazard is multiplicative with a unit increase in the covariate. Two common options for survival analysis include both proportional hazards models as well as accelerated failure time models, which assume that covariates increase or decrease the time in which a disease runs its course. These models are also largely parametric in nature. Given the endogeneity issues present in the model which make parametric estimation particularly suspect, it is thus preferable to resort to a proportional hazards model. Another benefit of the Cox Proportional Hazards Model is that it allows for consideration of covariates that change over time as long as the data is formatted in long form, meaning that changes are coded as a seperate observation at the time of the change.

Alongside the hazard function, another important component of the Cox model is the survival function, graphs of which will be displayed for the various survival models in the following section. A survival function can be thought of as the probability that 
time of death (or in this case. cancellation) is later than a certain point in time. All of the above information on survival functions is taken from Kleinbaum and Klein (2012), as well as Dobson and Barnett (2018), which also served as a reference for the various forms of Equation 1.3.

Survival analysis for FOX might have proven interesting given availability of more data during the period in question. FOX premiered substantially fewer shows during the early years due to the targeted campaign undertaken to establish footholds on specific days and under specific genres. Thus, only the Big Three are considered during the period in question.

\subsection{Empirical Results}

\subsubsection{Survival Analysis}

The results of the survival analysis are listed in Table 1.5. Coefficients must be interpreted in a different way from ordinary regressions. The sign of the coefficient represents whether or not the hazard ratio is increased or decreased, representing an increased or decreased risk of cancellation, respectively. The magnitude can be interpreted as the scale by which each variable changes the hazard ratio. Models of odd numbers in Table 1.5 represent survival analysis inclusive only of days of the week. Even-numbered models represent estimations including covariates for both days of week and genres. Friday is the baseline for days of the week, and Action/Adventure is the baseline for genre, meaning that the results can be interpreted relative to those days/this genre. It was difficult to choose an appropriate baseline, but the results relevant to the discussion of FOX were not sensitive to choice of baseline. 
Table 1.5: Survival Analysis (Cox Proportional Hazards) Results

\begin{tabular}{|c|c|c|c|c|c|c|}
\hline & \multicolumn{2}{|c|}{ NBC } & \multicolumn{2}{|c|}{$\mathrm{ABC}$} & \multicolumn{2}{|c|}{ CBS } \\
\hline & Model 1 & Model 2 & Model 3 & Model 4 & Model 5 & Model 6 \\
\hline \multirow[t]{2}{*}{ Sunday } & 0.489 & 0.170 & 0.022 & 0.152 & -18.782 & -18.301 \\
\hline & $(1.630)$ & $(1.185)$ & $(1.023)$ & $(1.165)$ & (6.97E-09) & (1.13E-08) \\
\hline \multirow[t]{2}{*}{ Monday } & -1.015 & $-1.302^{* *}$ & 0.135 & 0.831 & $-1.547^{* * *}$ & $-1.696^{* * *}$ \\
\hline & $(0.363)$ & $(0.272)$ & (1.144) & $(2.296)$ & $(0.213)$ & $(0.183)$ \\
\hline \multirow[t]{2}{*}{ Tuesday } & $-0.920^{*}$ & $-1.009 *$ & -0.122 & -0.009 & -0.670 & 0.053 \\
\hline & $(0.399)$ & $(0.365)$ & $(0.885)$ & $(0.991)$ & $(0.512)$ & $(1.054)$ \\
\hline \multirow[t]{2}{*}{ Wednesday } & -0.094 & -0.223 & 0.109 & 0.137 & -0.053 & 0.144 \\
\hline & (0.911) & $(0.800)$ & (1.115) & $(1.147)$ & $(0.948)$ & $(1.154)$ \\
\hline \multirow[t]{2}{*}{ Thursday } & $-1.730^{* * *}$ & $-1.805^{* * *}$ & $0.861^{*}$ & $1.005^{*}$ & -0.077 & 0.386 \\
\hline & $(0.177)$ & $(0.164)$ & $(2.366)$ & $(2.733)$ & $(0.926)$ & $(1.470)$ \\
\hline \multirow[t]{2}{*}{ Saturday } & $-0.674^{*}$ & $-0.909^{* *}$ & $1.160^{* * *}$ & $1.234^{* *}$ & 0.531 & $0.724^{*}$ \\
\hline & $(0.510)$ & $(0.403)$ & (3.188) & $(3.436)$ & $(1.700)$ & $(2.063)$ \\
\hline \multirow[t]{2}{*}{ Comedy } & & -0.217 & & 0.704 & & 0.097 \\
\hline & & $(0.805)$ & & $(2.021)$ & & $(1.102)$ \\
\hline \multirow[t]{2}{*}{ Drama } & & 0.216 & & 1.078 & & -0.052 \\
\hline & & $(1.241)$ & & $(2.940)$ & & $(0.950)$ \\
\hline \multirow[t]{2}{*}{ Documentary } & & & & & & $-2.365^{* *}$ \\
\hline & & & & & & $(0.094)$ \\
\hline \multirow[t]{2}{*}{ Legal/Police Drama } & & -0.934 & & 0.460 & & -0.611 \\
\hline & & $(0.393)$ & & $(1.583)$ & & $(0.543)$ \\
\hline \multirow[t]{2}{*}{ Other } & & -0.137 & & $1.783^{*}$ & & \\
\hline & & $(0.872)$ & & $(5.951)$ & & \\
\hline \multirow[t]{2}{*}{ Science Fiction/Fantasy } & & -0.417 & & $2.660^{*}$ & & -0.432 \\
\hline & & $(0.659)$ & & $(14.292)$ & & $(0.649)$ \\
\hline \multirow[t]{2}{*}{ Western } & & & & -0.061 & & -0.987 \\
\hline & & & & $(0.941)$ & & $(0.373)$ \\
\hline Sample Size & 84 & 84 & 95 & 95 & 96 & 96 \\
\hline$R^{2}$ & 0.240 & 0.294 & 0.151 & 0.221 & 0.358 & 0.440 \\
\hline
\end{tabular}

The main need for these results is to provide greater analysis into the insight that FOX is taking advantage of a shortcoming by networks, primarily by going for comedies on Sundays. A subsidiary goal is also to show areas of strength for the Big Three networks-days and genres that show strength under the various networks.

NBC shows strength across all models on Tuesdays, Thursdays, and Saturdays, with significantly negative coefficients. Thursdays were strong for NBC due to The Cosby Show and A Different World; Tuesdays were strong due to Matlock and Law 83 Order, and finally Saturdays were strong for The Golden Girls and Empty Nesters. This shows a habit displayed by NBC more than any other network during the time period: domination of certain days by stacking back-to-back, hit shows back to back. 
In the case of Thursdays and Saturdays, one of the hit shows was a spin-off of the other. ABC shows strength on no particular day, but shows weakness on Thursdays and Saturdays. Finally, CBS shows significant strength across specifications on Mondays. With respect to genre, ABC shows weakness with "Other" and "Science Fiction/Fantasy." Finally, CBS shows strength with respect to documentary series, with the cop documentaries Rescue 911 and Top Cops surviving more than two seasons. Overall, these observations confirm several that were made regarding the summary statistics, and draws attention back to the reasons in each case. Alongside this, there is a notable lack of evidence that Big Three networks have a positive association between shows airing on Sundays and survival. This provides evidence to confirm the hypothesis that there existed an opening for success for FOX on Sundays.

\subsubsection{Analysis of Survival Curves}

Analysis of the following Kaplan-Meier survival curves (see appendix) can assist to study general behaviors of certain networks regarding survival and failure regardless of day and genre. A curve is reported for each model listed in the regression table. Each stepwise point in the curve represents moving forward one season; every show has a $100 \%$ chance of survival then. In subsequent steps, the y-axis represents the survival probability to a later season given survival to the current season.

Due to the further explanation for death with the addition of genre, the survival curves for the even-numbered models have wider right-handed tails than their oddnumbered counterparts, meaning that when you remove the effect accounted for by genre in addition to day, your chances of survival increase. In the absence of any covariates, the tail is even tinier; the results of this test are not reported but available on demand. It might also provide insight into a common practice among networks: 
to shift shows onto less-popular days in later seasons as viewership declines. As day is accounted for, survival odds increase in the base function during seasons two and three, meaning that for those seasons in particular the effect of day of week has a marked effect. Shifts in the curve due to the addition of day and genre in the further right ends of the tails are relatively muted.

Between the different networks, one can interpret differences in curves as likelihood to renew a show beyond each season in question. All major networks are similar on the right end of the tail, but seasons two and three are of note. NBC shows the least likelihood of survival past a third season, and shares similarities with ABC in survival rates past a second season. Meanwhile, CBS appears highly likley to renew past a second season during the time period in question, but appears similar to other networks in reported survival rates for subsequent seasons.

\subsection{Conclusion}

This paper seeks to gain insights into the market for network television programming during the time period 1983-1993, in order to analyze how FOX managed to break the longstanding oligopoly of the Big Three primetime networks over content creation and broadcasting in the United States. A long trend of regulation and then deregulation helped to build and then subsequently undo the constraints which prevented a viable fourth option from entering the market. In order to gain a foothold in programming, FOX sought to compete on certain days using genres atypical from those used by the Big Three. Analysis of network television data taken from Brooks and Marsh (1999) using means including survival analysis provides useful insight into the structure built up by the Big Three to optimize revenue and maintain market share during the time period, while also providing a glimpse into certain days and genres which sat 
underutilized.

This analysis is particularly timely and relevant when considering the more recent changes in the market. While overall content creation and streaming is entirely decentralized by the internet, many media companies are seeing massive mergers which promise to continue the dynamic changes in media and entertainment over the course of the past 40 years. 


\section{Chapter 2}

\section{Blackjack or Bust: The Effect of New, Local Casino Construction on Housing Transaction Prices in Franklin County, OH}

\section{$2.1 \quad$ Introduction}

In the last two decades, there has been a growth in literature surrounding urban amenities. Many papers have investigated extensively the amenity value of local characteristics such as weather and climate change (Albouy, Graf, Kellogg, \& Wolff, 2016; Bin, Kruse, \& Landry, 2008; Maddison \& Bigano, 2003; Meier \& Rehdanz, 2017; Rehdanz \& Maddison, 2009; Timmins, 2007). Still others have asked the same question with regards to physical amenities of the cultural and historical variety (Borgoni, Michelangeli, \& Pontarollo, 2018; Franco \& Macdonald, 2018; Hicks \& Queen, 2016; van Duijn \& Rouwendal, 2013), alongside others focused on the amenity value of places of worship (Brandt, Maennig, \& Richter, 2014; Thompson, Butters, \& Schmitz, 2012). Some authors, such as Fortin, Hill, and Huang (2014) even measure the value of topics as novel as certain lucky and inauspicious numbers included in home addresses. Finally, the literature has also focused on amenities most directly related to standard 
recreational and entertainment activities such as professional sports, restaurants, and destination amenities such as ski lodges and forests. This literature intersects with the recent focus on amenity construction in cities. In recent years, many cities in the United States have solved the problem of decaying former industrial districts through the construction of vast new development projects on said sites.

There are many reasons behind the consideration of such districts as a problem; however the most common concern cited is crime related to synonymous "urban blight." The current administration has spoken about the issue at great length, linking decaying urban centers to crime and violence (Hains, 2016). The literature provides us with a few explanations for the rise in crime as a result of this so-called urban blight. Firstly, Becker (1968) and Ehrlich (1973) propose that crime arises as a result of a higher expected return from criminal activities versus legitimate ones. Framing this from the perspective of urban blight, one can imagine that when legitimate activities pack up and leave the expected return from seeking to engage in legitimate activities plummets relative to the alternative.

A commonly-cited explanation for the effect of physical decay on crime is the socalled "broken windows" theory proposed by Wilson and Kelling (1982), which argues that physical decay creates a mentality of social decay, which in turn inspires crime that causes more physical decay, begetting a self-perpetuating cycle. The solution proposed by the theory is aggressive policing of nuisance activities such as graffiti painting, noise complaints, and indeed broken windows as a way of reducing physical blight, and thus crime. While the latter theory is quite controversial, the proposed solution is still highly influential in political circles especially given the current law and order criminal justice approach by the federal government (Thusi, 2017).

The effect of crime on cities takes two glaring manifestations. The first is of course the effect that crime has on quality of life not only for those directly effected 
by it but by those who live in fear of criminal actions being taken against their person or property. It is in great part this latter effect which leads to the indirect effect that crime plays: the fear of criminal activity serves as a disamenity, driving down property values. Much of the literature supports this notion, with may papers carrying providing empirical evidence. (Boggess, Greenbaum, \& Tita, 2013; Ihlanfeldt \& Mayock, 2010; Pope, 2008). This could have a considerable effect on local tax revenue, given that property taxation is the primary means by which municipalities in the United States fund their activities. It is not entirely difficult to conclude that this reduction in property values has had a hand to play in the budgetary issues plaguing a variety of former industrial towns in the Midwest.

Efforts to improve the various issues associated with urban blight based upon redevelopment of specific areas have come to be known as "Targeted Area Redevelopment" (Iams, 2006). A recent example of such targeted efforts to redevelop blighted neighborhoods in a major American city can be seen with the Hudson Yards project in New York. The land currently occupied by the new development was once a former industrial district, full of vacated factory buildings and dockyards. The city, seeing an opportunity to redevelop this area and bring in further revenue, allocated tax breaks and other incentives to the tune of $\$ 6$ billion for use in the project. Alongside higherend housing, the development includes various architectural and cultural amenities, including a new $\$ 500$ million city-sponsored arts center (Paybarah, 2019).

More pertinent to the subject of this paper, however, is the fairly recent redevelopment efforts in the city of Columbus, Ohio-the epicenter of Franklin County, and a former industrial town heavily affected by the overall decline in manufacturing seen in the last half-century. Two major projects come to bear heavily on this paper: the Arena District project, and the Hollywood Casino. The Arena District project bears many similarities to the Hudson Yards project: in response to a blighted, post- 
industrial downtown neighborhood, a motley group of investors, local governments, and local businesses engaged in a multilateral effort to construct vast new amenities in place of said blighted buildings. The project began with the construction of a new arena for the Columbus Blue Jays NHL team, Nationwide Arena. Later phases included the construction of new housing developments, shops, and other common urban amenities. Tax incentives played a role here as well, with a public investment of $\$ 35$ million to improve roads and other infrastructure around the new district, and for other development means. One of the main selling points regarding public financing of the district was that the new commercial and residential activities would lead to an influx of additional tax revenue; indeed, from 1998 to 2006, property tax revenue from the redeveloped neighborhood increased from almost zero to $\$ 4.4$ million a year (Iams, 2006). While research does not exist for indirect increases in property values from redevelopment, inquiries such as that of Rossi-Hansberg, Sarte, and Owens (2008) (in their case focused on the Richmond, VA property market) find significant positive externalities on surrounding property values from localized urban redevelopment programs.

It is within this torrent of new construction and attempts at additional revenue generation that we find the origin of the Hollywood Casino, the central focus of this paper. At its inception, the casino was intended to be a major part of the new development in said project's later phases. As with other casino projects, one of the major justifications for new construction is additional tax revenue from the gambling activities taking place within. For another recent example in nearby Illinois, Governor J.B. Pritzker recently unveiled a plan to fund statewide improvement and redevelopment projects based upon optimistic projections regarding a fairly recent expansion in casino gambling (Munks \& Petrella, 2019). However, while the casino was eventually constructed in its current location within the western suburbs of Franklin County, 
an outcry from landlords and other stakeholders in the arena district quashed the original placement plans (K. R. Cox, 2016).

This paper will use the case of the introduction of the Hollywood Casino in Columbus to examine resultant issues related to property valuation and taxation. First, I will explore the literature surrounding potential mechanisms by which casino placement could feasibly affect housing prices. Secondly, I will summarize the data used, examine the econometric literature surrounding standard hedonic and repeat-sales models, and lay out the empirical model for the hedonic methods used in this paper. Then, using property transfer data from the Franklin County Auditor's office, I will examine the post-hoc effect of the placement of the Hollywood Casino on property values in Franklin County, $\mathrm{OH}$ using said standard hedonic method alongide a repeat-sales model and finally a hybrid model in the style of Case and Quigley (1991). Finally, I will examine the public finance implications of the casino placement, comparing realized average yearly local government revenues from 2013-2018 received by Franklin County and her subsidiary municipal governments from the Ohio casino revenue tax fund compared to the average yearly projected gains or losses in real estate revenue from the expected change in property values in the surrounding area.

\subsection{Literature Review}

A good segue into perspectives regarding casino placement comes from the example of the aforementioned resident outcry over the placement of a casino in the Stadium District in Columbus. The question is thus: why might residents reject this proposal?

At face value, one might see many benefits to the local placement of a casino. Firstly, the addition of new jobs might cause an increase in demand for local housing through the addition of more workers as well as higher incomes. As well, Wiley and 
Walker (2011) find significant, positive effects on local commercial property values from the placement of casinos, suggesting that casino placement is complementary to increased economic activity in surrounding businesses. It must also be stated that this paper is to the best of this author's knowledge the only analysis on the impact of casino placement on property values, commercial or residential. On the other hand, Garrett (2004) studies the question of whether casino placement leads to significant gains in local employment and income growth, and finds that positive effects are only realized when placement occurs in rural counties, where any gains would likely make up a large proportion of the county's economic activity. The same cannot be said for counties such as Franklin in Ohio, which are primarily urban/suburban communities in which casino activities would make up a substantially smaller proportion of economic growth. Lim and Zhang (2016), studying the very same question as Garrett (2004), find that growth in employment from casino placement dissipates when controlling for economic growth in neighboring and statewide localities. It is thus reasonable to conclude from the literature that price effects from employment and wage growth due to the placement of a casino such as the one at the focus of this paper, in an urbanized area, would likely have minor effects if any on surrounding property values through this causal mechanism.

A second reason why casinos could provide a positive effect on local property values comes from the indirect effect that additional tax revenue and associated improved public amenities could have on property values. In Ohio, casino tax revenue is distributed to local governments and school districts in statutory proportions of the total revenue collected from casinos. Further details of this schema can be found in later sections. From this observation and in conjunction with the literature, the most obvious locally-provided public amenity most directly related to casino revenues are public schools, which at face value should have a positive effect on local property 
values if school quality improves due to increased school budgets from casino revenues. The issue of casino revenue disbursements will be discussed in greater detail later in this paper, but the effect on schools must be considered. Ries and Somerville (2010) explores the question of how school quality affects property values in detail using district rezoning in Vancouver, finding that when accounting for long-run price trends, the effects of increased school quality only affect housing purchased by highincome families. This would suggest that improved school quality should not have a significant effect on property values in the area given that the sample area in this study is decidedly not high-income. Furthermore when considering an experimental variable that takes into account distance from the casino, and knowing that school funds are not distributed based on distance from the casino, this consideration should not significantly affect the results of this paper.

A third consideration which might lead one to assume a positive effect on property values from casino placement comes from the potential direct amenity effect that casino placement might have due to the sudden addition of a new activity for residents in the surrounding community. Casinos may also bring along new dining and recreational activities which could serve to draw in more residents into the surrounding communities. This is line with the work of Roback (1982), which proposes that locations with significant positive amenities should experience a corresponding positive rent gradient to compensate for the amenity value. To the best of this author's knowledge, there exists no literature which attempts to test the direct amenity value that casinos might have on local residential property values-the central goal of this paper being to investigate the net effect of casino placement on property values while exploring possible explanations for the observed effects. However, other feasibly similar amenities such as sports arenas and sports teams have been investigated thoroughly. With respect to the amenity values of arenas themselves, Tu (2005), Ahlfeldt 
and Maennig (2009), and Ahlfeldt and Maennig (2009) are examples of papers which have found a significant, positive effect on local housing prices from the placement of arenas. Meanwhile, research from B. R. Humphreys and Nowak (2017) finds that sports teams themselves generate significant negative effects on local property values that depreciate with distance from the home arena.

The reason why said amenities are feasibly similar has to do with the potential net effects that they could have on surrounding property values. In addition to the value homeowners could gain (or lose) from having access to a local arena or sports team, one can also imagine that the earlier positive effects from employment and increased business activity could apply as well. Alongside this comes the consideration of increases in crime from casinos as well. Here the focus is shifted quite clearly from reasons why casino placement could cause positive effects on housing prices to reasons why said placement could cause a decrease in housing prices. Crime is an obvious disamenity for local residents, increasing the expected costs of living in a particular area. Within the literature there exists a handful of papers dealing directly with the effects of casino activities on crime. Chronologically, the first paper in this grouping is Grinols, Mustard, and Dilley (2006), which explores the development of crime related to casino gambling over time. The authors find that while the immediate effects of casino activity on crime are modest, the effects increase with time. In the beginning, casinos bring increased, localized wage growth and development-factors which could potentially serve to decrease local crime rates. As an aside, this growth must also be viewed in the context of this paper through the lens of the entire county versus the local area-the effects on the county writ large might be small, but the neighborhood effects could be proportionally far larger. Over time however, the effects seen from increased payoffs to crime (ex. large amounts of winnings carried by lucky patrons) as well as the development of problem gambling behaviors could lead to a time-delayed 
increase in local crime. Two subsequent papers relate to these results in different ways. Reece (2010) finds that increased casino activity tends to reduce crime rates, which would seem to refute the findings of the earlier paper. However, the evidence presented is quite limited. Meanwhile, in direct response to the findings presented by Reece (2010), Kim, Pang, Bao, and Bosworth (2016) addresses the same question while tackling the issue of endogeneity between casino activities and the crime rate. To explain, suppose increased casino activities create an increase in the crime rate. Such an increase could feasibly then lower casino activities by driving away potential patrons. Kim et al. (2016) tackles this problem via the use of a simultaneous equations model, finding an increase in crime from casino activities that persists even after adjusting for visitors.

The data available on crime rates directly related to casino activities in Franklin County, $\mathrm{OH}$ is limited in that the Sheriff's office to the best of this author's knowledge does not release localized crime statistics-the data on casino-specific and total crime is only available at a county-wide level. However, we can see some small measure of evidence that the data seen in Figure 2.1 (source: Ohio Casino Control Commission and Ohio Department of Public Safety) seems to mirror the conclusions of Grinols et al. (2006) and Kim et al. (2016): even as the county-wide crime rate declines overall from 2013-2017, the casino-specific crime rate increases yearly by a substantial margin. However, these crimes are only a small proportion of the total crime rate county-wide, so how can it be said that they should have a significant effect on property values? The answer could very well lie with the perception of crime in the localized area. As has been previously stated, locals were already concerned with potential negative impacts such as increased criminal activity prior to the casino's opening. Any rapid increase in crime after the fact, however small in proportion to the county-wide crime totals, would serve to reinforce these prior beliefs. Indeed, an article from the local 
Figure 2.1: Total Crimes and Casino-Specific Crimes in Franklin County, OH 20132017

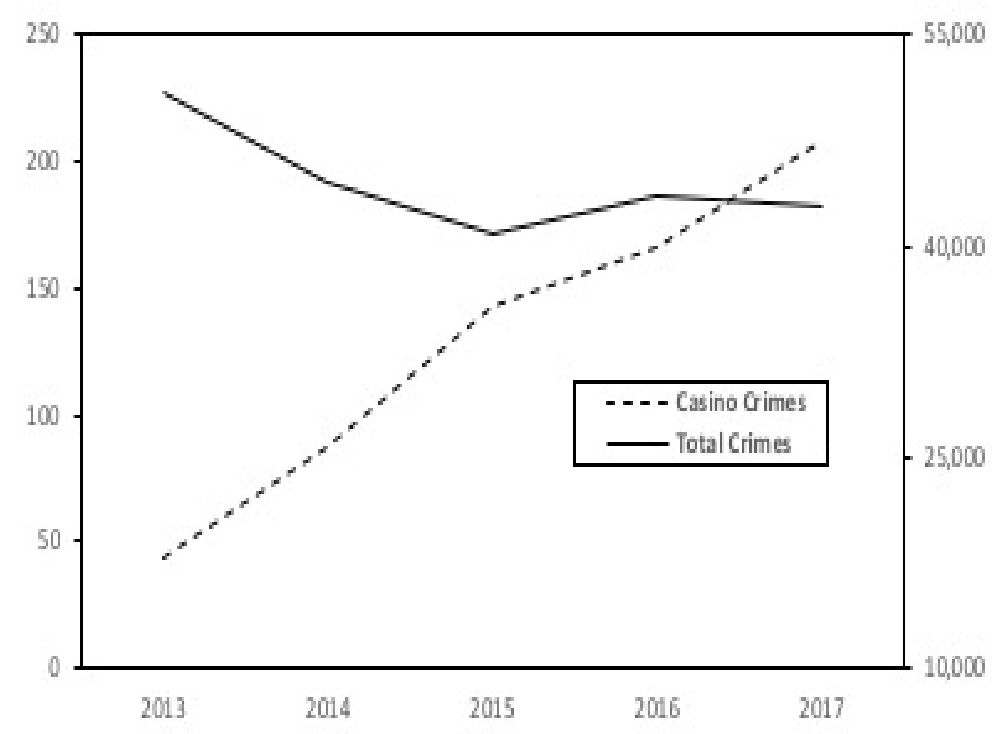

paper appeared right after the opening of the casino headlined "Crime Jumps around Casino" (Manning, 2012). Thus, it is perhaps the perception of crime from casino placement, rather than the actual felt effects of increased crime, which affects local property values. Papers such as Raya, Montolio, and Buonanno (2012) explore the effects of such perception, finding a significant effect on property values in Barcelona from 2004 to 2006 .

Overall, the literature suggests a complex picture of potential causal mechanisms by which casino placement and activities might influence local property values and thus property tax revenue. This paper's major contribution is to provide the first empirical insight into this question, in order to measure what the prevailing effect might be: do the positive effects outweigh the negative, or vice-versa? 


\subsection{Methods and Data}

\subsubsection{Franklin County, OH Real Estate Data}

The Franklin County, OH Auditor's Office provides a rich, publicly available data set comprised of both transactions as well as assessed-value data for all commercial and residential plots across the county from 1994-present. The empirical component of this paper will use a subset of the full sample of transactions data taken from 2001present. This is done in order to achieve relative balance around the year of casino placement (2012). I limit my sample to single-family homes on platted lots, which comprise the vast majority of homes in the area and allows me to eliminate farmhome plots in the sample, which would add unnecessary heterogeneity. Likewise, I eliminate any homes not sold under General Warrant deed, which allows me to largely focus on homes sold in normal transactions between parties lacking ties of kinship or friendship. Homes bought and sold in the same year are excluded in order to control for speculative land sales, or cases in which recent buyers were forced to sell due to some unforeseen crisis. Finally, all cases which contained incomplete information for at least one variable were dropped. In the case of the models with neighborhood fixed effects versus those without, the difference in sample size can be attributed to a lack of these neighborhood identifiers in the data. Upon examination of the documentation accompanying the literature, these missing values do not have any methodical reason behind their being missing, and thus it is assumed that omission of said information is randomly distributed. Subsequently, the lowest and highest $1 \%$ of all transactions with respect to sale value are dropped as well; this helps to exclude both extreme outliers on the higher end as well as family-to-family and friend-to-friend transactions on the lower end. 
Secondly, several variables were constructed from information available in the raw data set. The variables for the presence of a basement and attic are dummy variables taking a value of "1" when as house is observed to have a full basement or fully finished attic. The number of bathrooms present in the home is inclusive of both full and half bathrooms. The presence of a garage is a dummy variable taking a value of "1" in the presence of at least one basement or above-ground, attached garage space. Finally for values pulled only from the raw data, dummy variables (using the R package "dummies") are created for every year in the sample in order to account for yearly trends. Finally, the age of the home at the time of the transaction is generated by subtracting the year the home was built from the sale year.

Figure 2.2: Location of Single Family Homes Transacted from 2001-2012 on Platted Lots within 6 Miles of Hollywood Casino Columbus

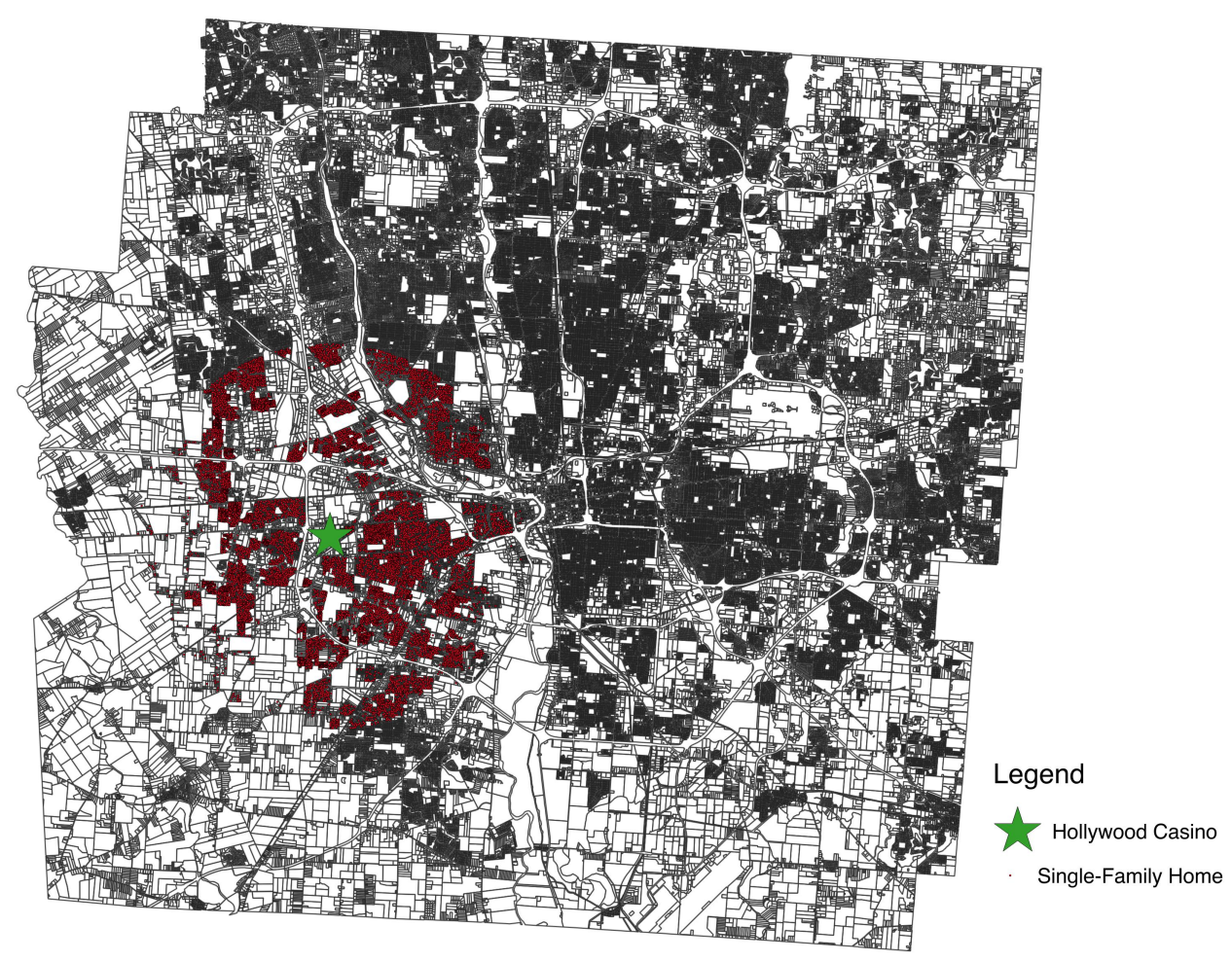


Using the "geosphere" package in R, the distance of each parcel to the Hollywood Casino site, measured in miles using the haversine formula for geospatial distance in conjuntion with longitudinal and latidudinal information included in the dataset as well as Google Maps (for the Hollywood Casino), is calculated. Another variable is then constructed using this distance as well as an indicator dummy for every year from 2012 onward. Further use of this information is used to limit the sample to all homes transacted in the time period within six miles of the Hollywood Casino site; many papers such as B. R. Humphreys and Nowak (2017) use similar distances as a measure, in that particular case 5 miles. Given that the area around the Hollywood Casino does not experience the same level of housing density, I expanded the distance by a mile to capture a larger sample of transactions. The locations of said homes in Franklin County relative to the casino are displayed in Figure 2.2. Finally, I construct a series of indicator variables representing rings around the casino site, again in the same manner as B. R. Humphreys and Nowak (2017) and others. Inspection of the price gradients in Figure 2.3 (constructed in much the manner of Linden and Rockoff (2008)) informs the ultimate decision to choose rings between 0 and 1.5 miles ("Ring One") as well as 1.5 to 3 miles ("Ring Two"). A variable representing a transaction having taken place within the rings (rings x post-2012) will serve as the experimental variable for each model in their own respective estimations, each estimation being exclusive of the other. Again looking to the price gradients in Figure 2.3, we should expect any positive or negative effects from the casino amenity to be increasing in proximity to the casino site (B. Humphreys \& Zhou, 2013). Also included for use in certain model specifications are indicators at a neighborhood level, as measured by the Franklin County Auditor. These neighborhoods most markedly do not contain roughly equal numbers of homes; the range of homes within each neighborhood in sample has a minimum of 1 and a maximum of 1,931 . 
Within the amenities literature, two general methods have been used to calculate the effect of an amenity on local property values. The first uses the distance between the amenity and the property. This method, according to Ross, Farmer, and Lipscomb (2009), is flawed in that it captures the effect of not only the amenity of interest but also of any other amenities located at a similar distance from the parcel. This leads to extreme sensitivity on the part of parameter estimates with respect to landmark selection. Ross et al. (2009) suggests a method which uses longitude and latitude to measure the precise location of each parcel, rather than the mere distance to an amenity. This is near-identical to the process by which the ring variables used in this paper are chosen.

Figure 2.3: Price Gradient, Combined Sample within 6 Miles of Hollywood Casino

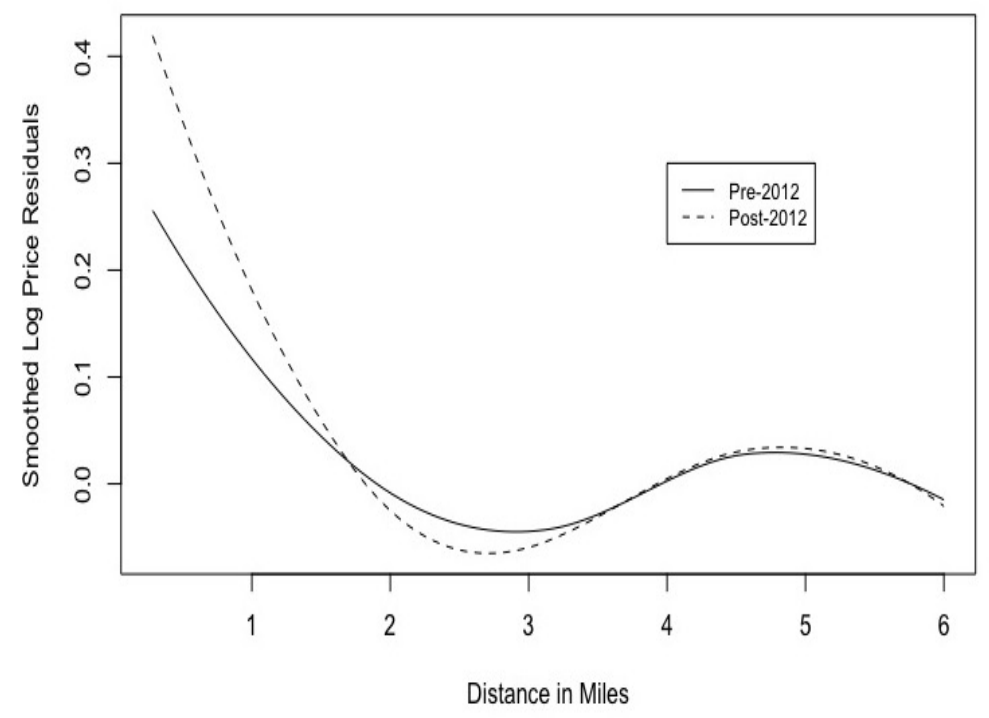

The summary statistics are displayed in Table 2.1. Of the 28,120 total transactions which take place within the 6-mile area during the time period in question, 12,003 involve properties being sold more than once. The average age at the time of sale, 37.12 , is in line with other papers using single-family home data in a variety of locations. The average sale price over the transaction period indicates a relatively 
Table 2.1: Summary Statistics

\begin{tabular}{lrrrr}
\hline Variable & Mean & Std Dev & Min & Max \\
\hline Sale Price (in Thousands) & 167.2 & 94.2 & 15 & 672 \\
Plot Acres (GIS Calculated) & 0.215 & 0.355 & 0.016 & 23.06 \\
\# of Bedrooms & 3.141 & 0.603 & 0 & 7 \\
\# of Bathrooms & 2.273 & 0.846 & 0 & 8 \\
Floor Area (Sq. Ft.) & 1552 & 538.198 & 320 & 6627 \\
Age at Transaction & 37.12 & 31.353 & 0 & 218 \\
Distance from Casino & 3.703 & 1.42 & 0.283 & 6 \\
Categorical: & & & & \\
Has a Finished Basement & 0.615 & 0.486 & 0 & 1 \\
Has a Finished Attic & 0.03 & 0.171 & 0 & 1 \\
Has a Garage & 0.652 & 0.476 & 0 & 1 \\
Sale Year & 2009 & 5.633 & 2001 & 2019 \\
Distance from Casino $<1.5$ Mile & 0.069 & 0.254 & 0 & 1 \\
\hline Sample Sizes: & & & & \\
Transactions & 28,120 & - & - & - \\
Repeat Sales & 12,003 & - & - & - \\
\hline
\end{tabular}

lower-value set of homes; this is in line with the fact that communities present in sample such as Westgate are considered to be good choices for first-time home buyers: lower-cost, suburban neighborhoods.

One opportune fact about the area in which all of these transactions take place is that there is a relative dearth of other amenities in the area which could serve to confound the results. One of the main arguments made in favor of inviting the casino into southwestern Franklin County was that it could potentially attract new businesses to an area lacking much in the way of commercial activity. This dearth began with the twenty year decline and ultimate closure of the Westland Mall, which was located right across from the future casino plot, in 2012. The mall was considered to be "dead" around the year 2003, when many anchor retailers began to close locations. Given that this is the same year that the casino opened, it is hard to disentangle the potential effects from both occurrences with $100 \%$ accuracy; however, later placebo 
tests carried out in Tables 2 and 3 using random distribution of the experimental variable "Ring 1 (2) x post-2012" show that said random placement variable does not prove significant. In the case that the declining mall served as a disamenity, we would most likely see the effect reflected in this variable across the period of decline.

Another local factor which contributes to the reliability of the results in this paper is the general increase in property values during the post-2012 period across Franklin County, as shown by the logged price difference index plotted in Figure 2.4. This is owing to the fact that any negative effect on prices in the post-2012 period will be in direct opposition to county-wide trends in property values during the same period.

Figure 2.4: Logged Price Differentials Index, 2001-Present

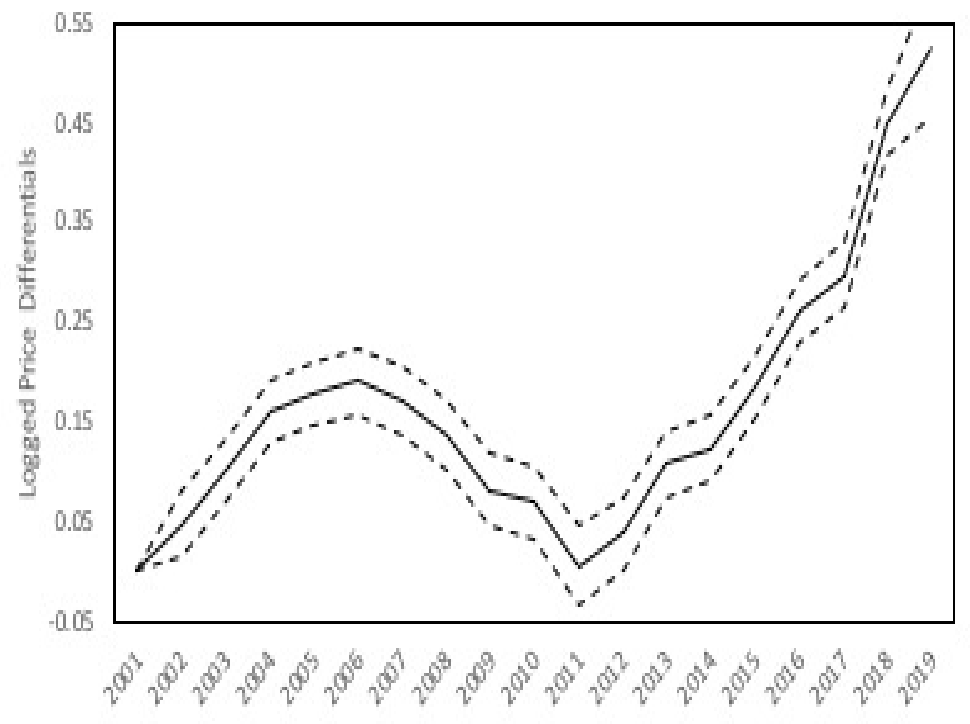

Certain geographical and other factors (ex. convenient access to shopping and workplaces) could indeed serve to create problems for the standard hedonic estimations through model misspecification. The primary benefit of including the RSR and hybrid estimations in the results of this paper is that by design the procedure controls for said factors. Thus, as a robustness check with respect to the same one can examine the results of the RSR and hybrid models in comparison to the standard 
hedonic results.

\subsubsection{Empirical Methods}

The first component of the empirical results presented in this paper will largely follow the empirical methodology used in B. R. Humphreys and Nowak (2017); that is, two general kinds of models will be estimated: an initial standard hedonic model alongside a repeat-sales model. The first type will be estimated using homes within the sample which have only experienced one sale within the time period under examination. The second hedonic estimation will be carried out with the full sample inclusive of both homes sold once as well as homes sold multiple times. Each equation will be estimated both with and without neighborhood-level fixed effects, and using the rings measure as the variable of interest.

The basis for all of the empirical considerations in this paper is the standard hedonic model originating in the work of Rosen (1974) and Nelson (1978). The remainder of the empirical model (the specification equations as well as the "mixed model") takes after the example of Jones (2010), itself a practical exposition of the theoretical basis proposed by Case and Quigley (1991). Consider a sample of H houses over times $t \in[1, T]$. The sale price of each house $h$ in the sample at time $t, P_{h}^{t}$, can be represented by

$$
P_{h}^{t}=\alpha+\boldsymbol{\beta} \mathbf{X}_{h}^{t}+\gamma \mathbf{d}_{h}^{t}+\Theta \nu_{h}^{t}+\varepsilon_{h}^{t}
$$

where $\mathbf{X}_{h}^{t}$ is a $H \times K$ matrix containing characteristics for each house being sold, $\mathbf{d}_{h}^{t}$ is a $T \times H$ matrix containing fixed effects equal to 1 for the period in which the sale takes place and 0 otherwise, $\nu_{h}^{t}$ is a $2 \times H$ matrix containing the Ring 1 and Ring 2 Post-2012 variables. The coefficient $\Theta$ is representative of the time-independent hedonic price of the variable of interest, and is thus the main focus of these empirical 
exercises. $\varepsilon_{h}^{t}$ represents the error of the model at time $t$. The sample of $H$ homes can be decomposed into the following subsets: homes $s \in[1, S]$ which only sold once (the "singles set"), and homes $j \in[1, J]$ which sold more than once. Of the latter, we can further separate out the individual transactions of homes sold more than once (the "repeat set") into earlier sales in time $t$ and later sales in time $\tau$. There is some overlap between the two, as a second price in one sale could indeed be a first price in a subsequent sale. Using this information, one can then construct the following system of equations:

$$
\begin{gathered}
P_{i}^{t}=\alpha+\boldsymbol{\beta} \mathbf{X}_{i}^{t}+\gamma \mathbf{d}_{i}^{t}+\Theta \nu_{i}^{t}+\eta_{i}+e_{i}^{t}, \\
P_{j}^{t}=\alpha+\boldsymbol{\beta} \mathbf{X}_{j}^{t}+\gamma \mathbf{d}_{j}^{t}+\Theta \nu_{j}^{t}+\eta_{j}+e_{j}^{t}, \\
P_{j}^{\tau}=\alpha+\boldsymbol{\beta} \mathbf{X}_{j}^{\tau}+\gamma \mathbf{d}_{j}^{\tau}+\Theta \nu_{j}^{\tau}+\eta_{j}+e_{j}^{\tau},
\end{gathered}
$$

Note that the error terms for these equations are decomposed from Equation 2.1 into two parts: the time-independent specification error $\eta_{h}$ and the white-noise error term $e_{h}^{t}$. Th specification error comes from the fact that we do not know the true functional form of the hedonic function which transforms the characteristics and time dummies into the observed transaction prices. Due to this limitation, I assume the function to be linear, with an error term to absorb misspecification.

The formal RSR model can now be drawn out by subtracting the price at time $\tau$ from the price at time $t$ to yield

$$
P_{j}^{\tau}-P_{j}^{t}=\gamma \boldsymbol{\delta}_{j}^{\tau}+\Theta n_{j}^{\tau}+e_{j}^{\tau}-e_{j}^{t}
$$

where $\boldsymbol{\delta}_{j}^{\tau}$ is a $T$ x H matrix of dummy variables equal to 1 for the second sale year, -1 for the first sale year, and 0 otherwise-essentially the difference between the similar 
terms in Equations 2.1 and 2.2. Likewise, $n_{j}^{\tau}$ is a similarly-constructed variable for the $\nu_{j}^{t}$ variables in the earlier system of equations, equal to 1 for each property set where time $t<2012$ and time $\tau \geq 2012$; and zero otherwise.

The volatility present in Figure 2.4 creates cause for concern as to the suitability of an RSR specification as a good substitute for the hedonic price function, as such volatility can indicate that the sample of re-sold homes possess different characteristics than the sample of single-transaction homes. Furthermore, there thus exists a concern as to the relative stability of our hedonic prices for each characteristic in $\mathbf{X}_{h}^{t}$ across the sample time period. To test whether or not the hedonic function is indeed stable in this respect I estimate a mixed model to analyze the amount of time variation in the price function of log square footage (the elasticity of dwelling size) of homes across the entirety of Franklin County during the period in question following the example of B. R. Humphreys and Nowak (2017). This model can be expressed as

$$
p_{n c t}=\alpha_{c}+\delta_{t}+\gamma_{t} \log S q f t_{n c t}+\varepsilon_{n c t},
$$

where the neighborhood-level fixed effects $\alpha_{c}$ and the hedonic price of logged housing size $\gamma_{t}$ are treated as random variables drawn from a normal distribution. Upon inspection of Table 2.2 (results produced using the "lme4" package in R), one can see that the variance of the time-dependent hedonic prices for the size of the home, $E\left(\gamma_{c}^{2}\right)$, is far smaller than the variance of the time-independent neighborhood-level fixed effects, which suggests relative stability across the time period in question. 
Table 2.2: Mixed Model Results

\begin{tabular}{|c|c|c|}
\hline & Model 1 & Model 2 \\
\hline Distance & $\begin{array}{c}0.006^{*} \\
(0.002)\end{array}$ & - \\
\hline Distance x Post & $\begin{array}{l}0.009 * \\
(0.001)\end{array}$ & - \\
\hline Ring 1 & - & $\begin{array}{c}-0.004 \\
(0.016)\end{array}$ \\
\hline Ring 2 & - & $\begin{array}{l}0.019 \\
(0.012)\end{array}$ \\
\hline Ring $1 \times$ Post & - & $\begin{array}{l}-0.021 \\
(0.024)\end{array}$ \\
\hline Ring $2 \times$ Post & - & $\begin{array}{c}-0.040^{*} \\
(0.019)\end{array}$ \\
\hline $\mathrm{E}\left(\alpha_{t}^{2}\right)$ & 2.949 & 2.964 \\
\hline $\mathrm{E}\left(\gamma_{c}^{2}\right)$ & 0.183 & 0.183 \\
\hline Observations & 112,752 & 112,752 \\
\hline RMSE & 0.293 & 0.293 \\
\hline
\end{tabular}

Note: Ring 1 is between 0 and 1.5 miles, and Ring 2 is between 1.5 and 3 miles.

Even still, another concern with the estimation of both models separately is that each is incredibly wasteful of the information present in the data of the other. Given this, I return now to the earlier Equations 2.1, 2.2, and 3. These equations comprise a system of equations which form the backbone of the aforementioned hybrid model. The amount of data we omit to form a model with minimum sample heterogeneity is minimized in this hybrid model, as the transformation renders an OLS model estimated using the data transformed via the following process robust to sample heterogeneity. Under the assumptions that for house $h=\{i, j\}, \mathrm{E}\left(e_{h}^{t}\right)=0, \operatorname{Var}\left(e_{h}^{t}\right)=$ $\sigma_{e}^{2}, \operatorname{Cov}\left(e_{i}^{t}, e_{j}^{t}\right)=\operatorname{Cov}\left(e_{h}^{t}, e_{h}^{\tau}\right)=0, \mathrm{E}\left(\eta_{h}\right)=0, \operatorname{Var}\left(\eta_{h}\right)=\sigma_{\eta}^{2}$, and $\operatorname{Cov}\left(e_{h}^{t}, \eta_{j}\right)=0$; the covariance matrix of the error structure is:

$$
\boldsymbol{\Omega}=\left[\begin{array}{ccc}
\left(\sigma_{\eta}^{2}+\sigma_{e}^{2}\right) \mathbf{I} & \mathbf{0} & \mathbf{0} \\
\mathbf{0} & \left(\sigma_{\eta}^{2}+\sigma_{e}^{2}\right) \mathbf{I} & -\sigma_{e}^{2} \mathbf{I} \\
\mathbf{0} & -\sigma_{e}^{2} \mathbf{I} & 2 \sigma_{e}^{2} \mathbf{I}
\end{array}\right]
$$


a matrix with dimensions $I \times 2 J$, and for which $\sigma_{\varepsilon}^{2}=\sigma_{\eta}^{2}+\sigma_{e}^{2}$, per the error assumptions and hereafter known as Identity 1 . Recall that $\varepsilon_{h}^{t}$ is simply equal to the error term present in the undecomposed hedonic model run using both repeat as well as single sales. Continuing the discussion of errors in the model, it can be shown that if the model specification error $\eta_{h}$ is equal to zero, or rather no misspecifications are made in the original hedonic equation, the hybrid model is equivalent to the hedonic model. Since this is not the case-every hedonic model introduces some measure of error-this model is an improvement in the estimation of hedonic prices.

Since it was assumed that the misspecification errors of the hedonic models were unrelated to the included variables themselves, Jones (2010) makes clear connections between the hybrid model and a random effects model. From this insight, the following strategy for a consistent estimate of $\Omega$ is developed. It involves firstly estimating a RSR model of the set of all repeat sales $n \in\left[1, N_{R S}\right]$ to obtain the residuals $\hat{\zeta}_{n}$. Note that the number $N_{R S}$ is distinct from $J$, the reason being that this number indexes the transaction, and not the home itself-some homes are sold more than once in the sample. Then, using these values to calculate the sum of squared residuals, one can then calculate the estimated variance of the error term, $\hat{\sigma}_{e}^{2}$ using the equation $\hat{\sigma}_{e}^{2}=\frac{1}{2} \operatorname{Var}\left(\hat{\zeta}_{n}\right)$, which can also be expressed as:

$$
\hat{\sigma}_{e}^{2}=\frac{1}{2}\left(\frac{1}{N_{R S}-T}\right) \sum_{j=1}^{J} \hat{\zeta}_{n}^{2} .
$$

The above estimation of $\hat{\sigma}_{e}^{2}$ can be shown to be consistent. Meanwhile, taking the residuals from the estimation of the combined hedonic model, one can find that

$$
\hat{\sigma}_{\varepsilon}^{2}=\left(\frac{1}{N-K-T-1}\right) \sum_{n=1}^{N} \hat{\varepsilon}_{n}^{2}
$$


Having obtained these values, the covariance matrix $\Omega$ can then be formed.

The next step is to obtain matrix $\mathbf{P}$, which can be calculated via the Cholesky decomposition of the matrix $\Omega^{-1}$, so that $\mathbf{P}^{\prime} \mathbf{P}=\mathbf{\Omega}^{-1}$. Matrix $\mathbf{P}$ can then be used to re-weight the data used, the rows of which are layered in the matrix $\mathbf{X}$ in the following manner: single transactions first, then first transactions in the repeat sales model (both inclusive of all variables in the hedonic models), and finally the RSR data-much in the same manner as Equations 2.1,2.2, and 2.3. Following this, the hybrid model can then be estimated via OLS in the same manner as the hedonic models; the entire process can best be viewed as a unique application of weighted Generalized Least-Squares.

\subsection{Regression Results}

\subsubsection{Hedonic Results}

To begin, I report the results for all of the basic hedonic regressions in Tables 2.4 and 2.3. Table 2.4 reports the results using all available data in the sample. Model 1 attempts to measure the hedonic price of the Rings x Post-2012 variable, while Model 2 is structured towards the same goal while controlling for the effects of the specific neighborhood in the vicinity of the casino. Models $3 \& 4$ mirror Models 1 \&

2 except that in place of the observed experimental variables, I have generated new variables of the same construct which are randomly placed across the entire sample regardless of pre or post 2012 status as a placebo test. The effect reported for said variables is analogous to the variable $\Theta$ in Equation 2.1. Table 2.3 reports the results of the same specifications as described above, this time using the single transactions data. All dependent variables, whether for price in the case of the standard hedonic 
models or the price differential in the case of repeat sales models, are logged; this has the implication of making the coefficients for the ring variables analogous to percent changes in prices.

Table 2.3: Hedonic Results-Single Transaction Sample

\begin{tabular}{|c|c|c|c|c|}
\hline & \multicolumn{2}{|c|}{ Treatment Models } & \multicolumn{2}{|c|}{ Placebo Models } \\
\hline & Model 5 & Model 6 & Model 7 & Model 8 \\
\hline \multirow[t]{2}{*}{ Ring 1} & $-0.168^{* * *}$ & $0.069^{* * *}$ & $-0.241^{* * *}$ & -0.013 \\
\hline & $(0.011)$ & $(0.015)$ & $(0.014)$ & $(0.017)$ \\
\hline \multirow[t]{2}{*}{ Ring 2} & $-0.209^{* * *}$ & $0.084^{* * *}$ & $-0.277^{* * *}$ & 0.014 \\
\hline & $(0.008)$ & $(0.0019)$ & $(0.009)$ & $(0.011)$ \\
\hline \multirow[t]{2}{*}{ Ring 1 x Post } & $-0.186^{* * *}$ & $-0.196^{* * *}$ & -0.007 & -0.006 \\
\hline & $(0.021)$ & $(0.019)$ & $(0.017)$ & $(0.017)$ \\
\hline \multirow[t]{2}{*}{ Ring $2 \times$ Post } & $-0.179^{* * *}$ & $-0.191^{* * *}$ & -0.003 & -0.006 \\
\hline & $(0.015)$ & $(0.010)$ & $(0.011)$ & $(0.008)$ \\
\hline Neighborhood Fixed Effects & $x$ & $\checkmark$ & $x$ & $\checkmark$ \\
\hline Observations & 16,117 & 15,824 & 16,117 & 15,824 \\
\hline$R^{2}$ & 0.486 & 0.780 & 0.480 & 0.774 \\
\hline
\end{tabular}

Upon inspection of both tables, one can clearly see robust results across all specifications in favor of the hypothesis that the casino generated negative a price differential equivalent to between minus $17-20 \%$ for the ring variables. This effect was implied in Figure 2.3, and the results here indeed confirm that observation-the ring variables have negative coefficients, indicating that being within the prescribed rings likely creates a negative effect on house prices. The magnitude of these effects is remarkably consistent across the different samples, with similar numbers reported for equivalent models using the single and combined samples.

A question arises of whether or not the area immediately around the casino always generated a negative effect on housing prices within the 6-mile radius of the sample, and if so whether this is feeding into the "Ring x Post" variables. To test this, I constructed the aforementioned placebo effects. The ring variables by themselves 
(that is to say, without interaction with the post-hoc indicator) test significant only in the absence of controls for neighborhood-level fixed effects, suggesting that certain neighborhoods near the casino tend to lower property values in the pre and post period regardless of inclusion in the rings. However, the results show robust evidence across specifications that the random placement of the post-hoc indicator does not test significant-meaning that there is a factor regarding being placed after the casino opening date of 2012 which causes these variables to be significantly positive (or negative).

Table 2.4: Hedonic Models-Combined Sample

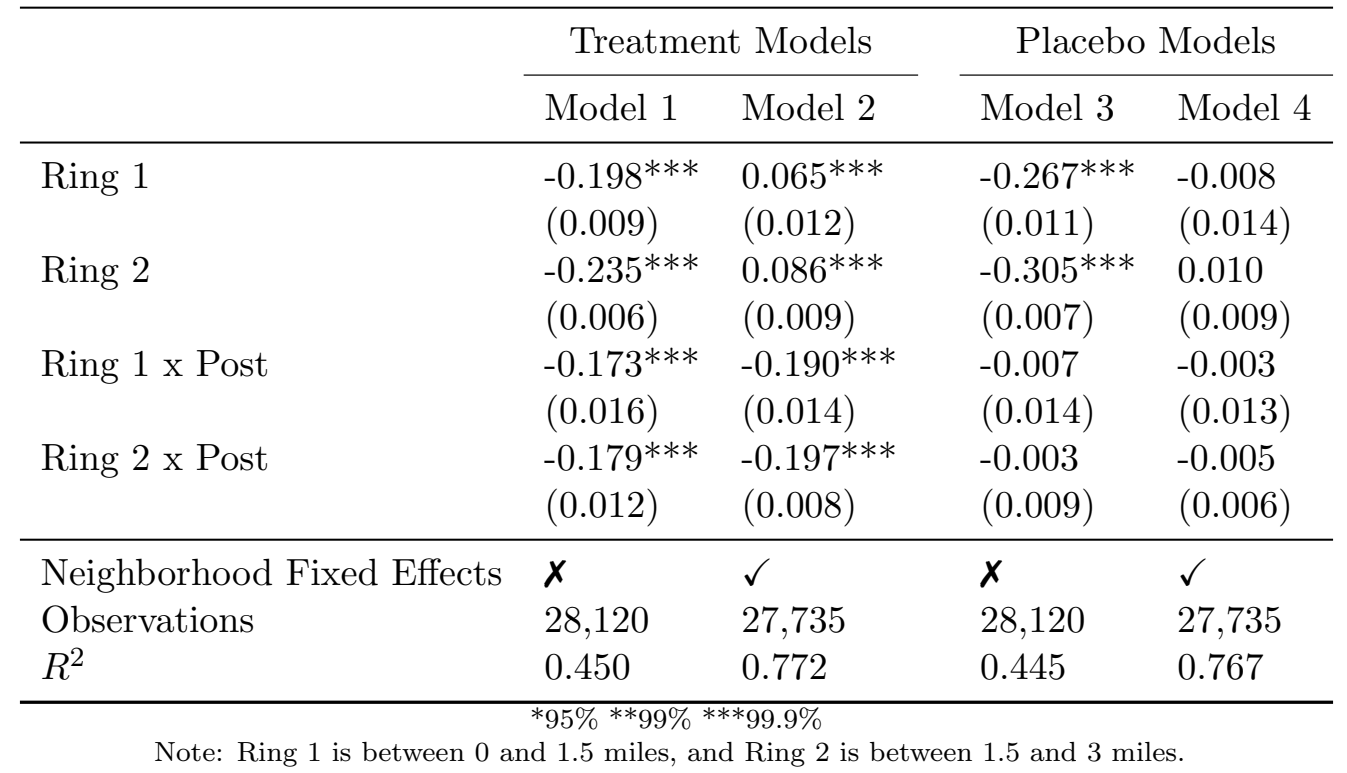

\subsubsection{RSR and Hybrid Model Results}

The results for the RSR specifications are shown below in Table 2.5; they show a striking similarity to the results shown for the hedonic models discussed previously, save for the slightly lower magnitude of the "Ring 1 x Post" variable, which is about 3-6\% 
lower than seen in said previously reported results. This suggests that homes sold in the single transaction sample within the first ring could serve to amplify the negative effects of casino placement. This observation is also supported by the comparison of the RSR Model to the Hybrid Model: with the addition of single transaction sales information, the effect of the "Ring 1 x Post" variable trends closer to the magnitudes seen in the standard hedonic models. No neighborhood-level fixed effects are included in either model, as the use of repeat sales renders their use unnecessary. The similarities suggest that the RSR model specification is indeed a good substitute for the traditional hedonic models, as discussed previously regarding the results of the mixed models in Table 2.2. The same stability in magnitude and significance of the experimental variables can also be seen in the results from the hybrid model, reported in Table 2.5.

Table 2.5: RSR and Hybrid Models

\begin{tabular}{lll}
\hline & RSR Model & Hybrid Model \\
\hline Ring 1 & - & $-0.201^{* * *}$ \\
& & $(0.013)$ \\
Ring 2 & - & $-0.233^{* * *}$ \\
& & $(0.007)$ \\
Ring 1 x Post & $-0.141^{* * *}$ & $-0.167^{* * *}$ \\
& $(0.023)$ & $(0.017)$ \\
Ring 2 x Post & $-0.180^{* * *}$ & $-0.186^{* * *}$ \\
& $(0.013)$ & $(0.009)$ \\
\hline Neighborhood Fixed Effects & $\boldsymbol{x}$ & $\boldsymbol{x}$ \\
Observations & 12,864 & 29,173 \\
$R^{2}$ & 0.147 & 0.999 \\
\hline
\end{tabular}

Note: Ring 1 is between 0 and 1.5 miles, and Ring 2 is between 1.5 and 3 miles. 


\subsection{Implications for Local Public Finance}

As stated before, legalization of casino gambling is often justified by citing the immense tax benefits granted to state and local governments from gambling activities. In Ohio, said benefits flow directly from a $33 \%$ tax on casino operator's gross revenue from each location. $51 \%$ of these funds are distributed to county governments statewide, with disbursements based on population. $34 \%$ of the funds are distributed to local school districts based on student enrollment. $5 \%$ of the funds are distributed to the cities in which each casino is located; and finally the remainder is split between a variety of enforcement, administrative, and gambling addiction resources (OH Revised Code Title 57:5753.01-5753.10, 2010).

There are a handful of papers in the literature which deal directly with the issue of casino gambling taxation. Most of the discussion present therein deals with the incidence and efficiency of said taxes as a means of revenue. Madhusudhan (1996) and Anderson (2005) discuss at length the regressive nature of the use of casinos as a source of revenue; however in Ohio the incidence of the tax is bourne directly by the business rather than the consumer in the form of a percentage of revenue. The only exception to this rule would be in the case where you have winnings, in which event the casino would withhold $4 \%$ of said winnings for the state. In Columbus, there is also an additional levy of $2.5 \%$ on winnings, for a total of $6.5 \%$. Madhusudhan (1996) also discusses the various factors by which casino gaming is a relatively inefficient means of generating revenue due to the cost of enforcement relative to other sources.

Alongside these discussions, this paper seeks to offer a rough estimate of another source of tax inefficiency in the form of property tax losses from the placement of the casino. While there are probable losses in the forms described by the earlier authors, and as the results will show from loss of property taxes as well, there are 
also theorized potential gains other than those realized through the casino revenue tax. Mason and Stranahan (1996) argues that dollars spent on gambling and dollars spent on shopping are substitutes, so that if the amount of tax you're charging per dollar on casino spending is higher than that being charged for consumer purchases in the form of a sales tax, you're generating more revenue. Meanwhile, people from other areas would also bring in both gambling and sales tax dollars which would not otherwise be seen without the casino amenity. For the purposes of this paper's analysis, I will be focusing on revenue specific to Franklin County, OH inclusive of its various school districts and cities. This allows for easier exclusion of sales tax and out-of-town visitor considerations given Franklin County's location far from a state border and relatively close to other casinos. Franklin County indeed charges a sales tax, however I will be treating the potential gains/losses from sales taxation as null to this analysis. Firstly, the additional revenues from consumers already within the sales tax base for Franklin County are already baked into casino revenues. Secondly, given the spatial distribution of casinos in Ohio, it is altogether likely that so-called "destination shoppers" from the wider consumer base the Hollywood Casino pulls from are already commuting to Columbus and Franklin County to make purchases anyway. Therefore, this group can be discounted in much the same way as the former group of local consumers.

Table 2.6 lists the amount of casino revenue tax disbursed per line item per year to Franklin County and its associated school districts and cities. The revenues are generally increasing, with an overall change of about $+\$ 4$ million from 2013 (the first full year of disbursement to Franklin County) to 2018. The average revenue over the course of this period of time was about $\$ 27.7$ million.

Taking this into account alongside the estimated coefficients from the various models, I construct Table 2.7, which shows the difference between the yearly property tax 
Table 2.6: Local Disbursements by Line Item and Year

\begin{tabular}{|c|c|c|}
\hline Y ear & Revenue Source & Dollar Amount (in Thousands) \\
\hline \multirow[t]{5}{*}{2013} & County Disbursement & $\$ 6,747.00$ \\
\hline & Columbus City Disbursement & $\$ 6,747.00$ \\
\hline & School Disbursement (County Total) & $\$ 8,548.00$ \\
\hline & Host City Disbursement & $\$ 3,506.00$ \\
\hline & TOTAL & $\$ 25,549.00$ \\
\hline \multirow[t]{5}{*}{2014} & County Disbursement & $\$ 7,254.00$ \\
\hline & Columbus City Disbursement & $\$ 7,254.00$ \\
\hline & School Disbursement (County Total) & $\$ 9,627.00$ \\
\hline & Host City Disbursement & $\$ 3,472.00$ \\
\hline & TOTAL & $\$ 27,607.00$ \\
\hline \multirow[t]{5}{*}{2015} & County Disbursement & $\$ 7,112.00$ \\
\hline & Columbus City Disbursement & $\$ 7,112.00$ \\
\hline & School Disbursement (County Total) & $\$ 9,646.00$ \\
\hline & Host City Disbursement & $\$ 3,399.00$ \\
\hline & TOTAL & $\$ 27,268.00$ \\
\hline \multirow[t]{5}{*}{2016} & County Disbursement & $\$ 7,373.00$ \\
\hline & Columbus City Disbursement & $\$ 7,373.00$ \\
\hline & School Disbursement (County Total) & $\$ 10,128.00$ \\
\hline & Host City Disbursement & $\$ 3,546.00$ \\
\hline & TOTAL & $\$ 28,420.00$ \\
\hline \multirow[t]{5}{*}{2017} & County Disbursement & $\$ 7,355.00$ \\
\hline & Columbus City Disbursement & $\$ 7,355.00$ \\
\hline & School Disbursement (County Total) & $\$ 9,795.00$ \\
\hline & Host City Disbursement & $\$ 3,611.00$ \\
\hline & TOTAL & $\$ 28,114.00$ \\
\hline \multirow[t]{5}{*}{2018} & County Disbursement & $\$ 7,684.00$ \\
\hline & Columbus City Disbursement & $\$ 7,684.00$ \\
\hline & School Disbursement (County Total) & $\$ 10,201.00$ \\
\hline & Host City Disbursement & $\$ 3,691.00$ \\
\hline & TOTAL & $\$ 29,259.00$ \\
\hline
\end{tabular}

revenue foregone by Franklin County versus the average local tax revenue generated by casino gambling. The estimates for foregone property tax revenue were calculated by first multiplying the coefficients by the "Rings x post-2012" variable, and then taking that as the percentage difference between the value before and after. This 
number could then be used with the assessed value of every property within 6 miles of the casino as of 2011 (right before casino placement) to get a reasonable estimate of the dollar amount by which property values declined. Finally, this number was multiplied by the effective tax rate-a number given in the raw data set-as well as the adjustment factor for property value (30\% for each home). The sum of this value across all homes within 6 miles of the casino with respect to the coefficients from each model yields the results reported in Table 2.7.

Table 2.7: Casino Tax Revenue vs. Foregone Property Tax Revenue

\begin{tabular}{llll}
\hline $\begin{array}{l}\text { Source Model for } \\
\text { Revenue Loss }\end{array}$ & $\begin{array}{l}\text { Neighborhood } \\
\text { Fixed } \\
\text { Effects? }\end{array}$ & $\begin{array}{l}\text { Dollar } \\
\text { Amount }\end{array}$ & $\begin{array}{l}\text { Amount } \\
\text { Less } \\
\text { Average } \\
\text { Casino Tax } \\
\text { Revenue }\end{array}$ \\
\hline $\begin{array}{l}\text { Average Annual } \\
\text { Casino Tax Revenue, } \\
\text { 2013-2018 }\end{array}$ & & $\$ 27,702.83$ & - \\
\hline $\begin{array}{l}\text { Pooled Hedonic } \\
\text { Model }\end{array}$ & No & & \\
& Yes & $\$ 44,969.00$ & $\$ 17,266.17$ \\
\hline $\begin{array}{l}\text { Single Transaction } \\
\text { Hedonic Model }\end{array}$ & No & $\$ 49,878.00$ & $\$ 22,175.17$ \\
\hline $\begin{array}{l}\text { Repeat Sales Model } \\
\text { Hybrid Model }\end{array}$ & - & $\$ 39,950.00$ & $\$ 12,247.17$ \\
\hline $\begin{array}{l}\text { Average Foregone } \\
\text { Additional Revenue }\end{array}$ & - & $\$ 50,168.00$ & $\$ 22,465.17$ \\
\hline \multicolumn{2}{c}{$\begin{array}{l}\text { Sources: Ohio Department of Taxation and Franklin County, OH Auditor's Office } \\
\text { Note: dollar figures in millions }\end{array}$} & \\
\end{tabular}

These results indicate that the average yearly property tax losses associated with casino placement exceed the average yearly amount generated by on average $\$ 13.8$ million. There are reasons to believe this number may be either inflated or understated. With regards to the former, there might very well be factors which were 
impossible to effectively control for, such as increased commercial activity in the given area, which increased local sales tax revenues due to more local versus outof-area buying. However, the businesses that opened up near the casino are mostly recreational facilities and restaurants-not places of business which directly compete with online and out-of-area merchants. A case could be made in these instances that there is a not-insignificant increase in income as discussed in previous sections; this effect is difficult to measure given available data. With regards to the latter-the notion that the estimates of losses could be understated-I also look to the sales tax mechanism. While there is revenue gained due to the higher tax on casino revenues versus consumer sales, the local community is still losing local sales tax dollars due to the substitution of gambling for consumer purchases, and thus these losses would amplify the amount of foregone additional revenue reported in Table 2.7.

\subsection{Conclusion}

This paper seeks to both estimate the effect on residential property values from the placement of a casino in the local area as well as to extend these results into real dollar amounts of property tax foregone by the placement of the casino, which is a novel extension of related literature on casino gaming and taxation. Franklin County, Ohio is a perfect case for this analysis due primarily to easy access to transactions data. As well, the placement of the county far away from any borders and relatively close to competing casinos allows for the control of any additional sales tax revenue from out-of-state gamblers.

In order to accomplish this task, a multitude of models are estimated using a standard hedonic, RSR, and hybrid approach in the mold of Case and Quigley (1991), respectively. The coefficients of certain model variations are then used to calculate 
the percentage change in property values around the casino, which is finally used to estimate the difference between tax revenues gained from casino revenues and lost due to the disamenity value of the casino.

The results, both consistent in significance and magnitude, show ample evidence that casino placement generated a disamenity value equal to about a 6-7\% decline in value with each additional mile of proximity for homes sold within six miles of the casino placement site following the placement year of 2012. Placebo measures of the "Distance x Post-2012" experimental variable fail to test significant at any standard level, providing an extra layer of robustness to my results. The difference between the average additional tax revenue from 2013-2018 and the foregone property tax revenue is indeed negative in the range of about $\$ 12-14$ million in foregone property tax revenue.

This paper contributes to the extant literature in that it challenges the notion that casino gambling is an obvious revenue-positive development for cash-strapped municipal governments. While the results are by no means perfect, they provide a novel insight into the public finance implications of casino placement, opening up a new line of research into an issue pertinent to numerous communities across the country. 


\section{Chapter 3}

\section{Why Go Home? The Impact of Pearl Jam's "Home Shows" on Hotel Demand}

Coauthored with Joshua Hall

Department of Economics

John Chambers College of Business and Economics

West Virginia University

Pearl Jam is one of the most popular bands from the 1990s. Rolling Stone named them one of fourteen 'New Immortals' when updating their top 100 all-time great artists list in 2013 (Rolling Stone, 2013). Founded in Seattle in 1990 (Pearl Jam, 2011), they are associated with the so-called 'grunge' movement that came out of the Pacific Northwest in the early 1990s (Yarm, 2011). According to the Recording Industry Association of America (2020), Pearl Jam has sold over 30 million albums in their career. A 2011 readers poll in Rolling Stone named them as one of the Top 10 live acts of all-time (Rolling Stone, 2011).

Beyond their music, Pearl Jam is known for its activism, with one scholar calling them the 'conscience of arena rock' (Weglarz, 2016). In the mid 1990s, the band 
took on what they saw as Ticketmaster's excessively high service fees and effective monopolization of concert venues in the United States (Boehlert, 1995). In 2006, the band set up a nonprofit called the Vitalogy Foundation to support their philanthropic efforts. With $\$ 3$ per ticket from every Pearl Jam concert, the foundation supports non-profit organizations trying to improve their communities in Seattle and around the United States (Millman, 2018). In January of 2018, Pearl Jam announced two concerts - dubbed the "Home Shows" - to be held in Seattle in August to raise awareness and funds to combat homelessness in Seattle (Kreps, 2018). A 2018 US Housing and Urban Development study found that Seattle had the third-highest homeless population of any US city (Henry et al., 2018).

Held at Safeco Field, the home of the Seattle Mariners, the two concerts held on August 8th and August 10th were estimated to be the largest headlining concert event in Seattle since the Rolling Stones' two-night show at the Kingdome in 1981 (Shafer, 2018). The stadium seats approximately 45,000 for concerts. With shows only a day apart, the sold-out concerts could have brought between tens of thousands of fans to Seattle, depending on how many fans purchased tickets to both shows. The fund raising goal of the concerts was $\$ 10$ million, with Pearl Jam providing matches up to $\$ 960,000$ for donations made by fans when purchasing tickets (Land, 2018). Ultimately, over $\$ 11.5$ million was raised for homelessness through the Home Shows (Krouoderova, 2018).

The festival-like nature of the Home Shows meant that Seattle may have benefited beyond the $\$ 11.5$ million in donations. The timing of the concert in early August, combined with a planned off-day between the two concerts, made it ideal destination for Pearl Jam fans looking to travel see Pearl Jam during the 2018 tour. In addition, since 1995 Pearl Jam had offered tickets to its fan club members prior to making tickets available to the general public (Boehlert, 1995). This allowed out-of-state and 
out-of-country Pearl Jam fans to buy tickets for both shows and plan an extended trip to Seattle. This maximizes the impact on hotel demand, since it minimized the leakages from residents, "time switchers," and "casuals" (Crompton, Lee, \& Shuster, 2001). ${ }^{1}$

In this paper we estimate a large portion of the economic impact associated with Pearl Jam's Home Shows by examining daily hotel data on the Seattle metropolitan area. While concert visitors spend dollars on food and shopping, the largest portion of their spending that is not displacing spending by locals is on hotel nights (Heller, Matheson, \& Stephenson, 2018). The economic impact of cultural events such as concerts crucially depends on the ability to draw visitors from outside the area (Hodur, Bangsund, Leistritz, \& Kaatz, 2006). That is because spending by local residents on the event is likely just substituting for other forms of entertainment (Baade \& Matheson, 2001).

We estimate the economic impact of Pearl Jam's Home Shows for two reasons. First, the impact of the Home Shows on the city of Seattle extend beyond raising awareness and charitable donations for homelessness. To preview our results, we find that the Pearl Jam Home Shows were associated with an increase in hotel demand that increased both the average room rate and occupancy. As a result, we estimate that the Home Shows increased lodging tax revenues in King County (Seattle's home county) to the tune of $\$ 9$ million. Second, the unique nature of these back-to-back concerts, combined with Pearl Jam's devoted fan base and unique ticket distribution method, provide a 'best case' scenario for how musical events can contribute to local economies. We find that Pearl Jam's Home Shows increase daily hotel revenue on

\footnotetext{
1 "Time switchers" are people who had already planned to attend Seattle in 2018 but changed their trip to coincide with the concert. Casuals are individuals who were already visiting Seattle and found out about the concerts and decided to go. Given the sell-out of the concert in advance, casuals are effectively zero in this case.
} 
concert days by $\$ 8.9$ million. Our work thus contributes to the literature on the economic impact of concerts and cultural events (Bracalente et al., 2011; T. Gabe, 2016; T. M. Gabe \& Lisac, 2014; Gazel \& Schwer, 1997; Senior \& Danson, 1998).

We proceed as follows. Section 3.1 discusses our daily hotel data and empirical approach. Section 3.2 presents our baseline results, while Section 3.3 presents placebo results. Section 3.4 concludes.

\subsection{Data and Methods}

The data used within this paper are nightly hotel demand data provided by STR, a firm that tracks global hotel supply and demand. In using hotel demand data to estimate the economic impact of events, we are following recent papers such as Heller et al. (2018), Depken and Stephenson (2018), Earhart and Stephenson (2018), and Bonneau and Hall (2020). These papers use daily hotel demand data from STR to estimate the effect of the Democratic and Republican National Conventions, sporting events in Charlotte, same-sex weddings in Savannah and Charleston, and football and basketball games in Morgantown, WV. Collins, Depken, and Stephenson (2020) and Sheehan and Stephenson (2020) focus on a number of events, including multi-day music festivals and find substantial effects of festivals on hotel demand and revenue. The period in question for the data is from January 1, 2004 to December 31, 2018, and the data is aggregated to the metropolitan area.

Given the geographic concentration of Seattle, this is a lesser issue than for other cities which may be more widespread geographically. Data is then also taken for home games played by three major sports teams in the area-the Seahawks of the National Football League (NFL), the Sounders of Major League Soccer(MLS), and the Mariners of Major League Baseball (MLB) -from the websites of either the league 
Table 3.1: Summary Statistics

\begin{tabular}{lrrrr}
\hline \hline Statistic & Mean & St. Dev. & \multicolumn{1}{c}{ Min } & \multicolumn{1}{c}{ Max } \\
\hline Full Sample (N =5479) & & & & \\
\hline ADR & 124.52 & 26.63 & 67.82 & 234.11 \\
Occupancy & 70.74 & 15.22 & 25.41 & 98.50 \\
RevPar & 90.83 & 35.56 & 19.71 & 228.41 \\
Supply & 40,207 & 2,908 & 35,254 & 48,667 \\
Demand & 28,534 & 6,861 & 9,390 & 46,007 \\
Revenue (in thousands) & $3,702.66$ & $1,635.46$ & 727.43 & $10,770.98$ \\
August (N =465) & & & & \\
\hline ADR & 143.61 & 32.46 & 93.83 & 234.11 \\
Occupancy & 86.46 & 8.36 & 54.51 & 98.48 \\
RevPar & 125.24 & 34.79 & 55.90 & 228.41 \\
Supply & 40,4180 & 3,027 & 36,012 & 47,155 \\
Demand & 34,985 & 4,573 & 21,426 & 46,007 \\
Revenue (in thousands) & $5,141.37$ & $1,767.22$ & $2,051.95$ & $10,770.98$ \\
Week of Concert (N $=7)$ & & & & \\
\hline ADR & 211.61 & 19.33 & 178.76 & 234.11 \\
Occupancy & 90.52 & 8.32 & 73.31 & 97.56 \\
RevPar & 192.86 & 33.11 & 131.05 & 228.41 \\
Supply* & 47,155 & 0.000 & 47,155 & 47,155 \\
Demand & 42,688 & 3,924 & 34,571 & 46,007 \\
Revenue (in thousands) & $9,094.38$ & $1,561.61$ & $6,180.08$ & $10,770.98$ \\
\hline *
\end{tabular}

*Supply constant over course of concert week.

or the individual teams, and then converted to indicator variables for the days on which games fell. The variables of interest are occupancy, revenue per available room (RevPar), average daily room rates (ADR), demand, supply, and total revenue (in thousands of dollars). Occupancy is the proportion of available rooms occupied on any given day, ADR is the total revenue divided by the number of rooms sold (demand), and revenue per room is the total revenue divided by the number of available rooms. Summary statistics for this set of covariates is found in Table 3.1. This includes summary statsitics for three different subsets: the total sample, sample days 
in August, and the week of the concert.

The summary statistics show that on average, $71 \%$ of rooms are full on any given night in Seattle during the sample period, compared with $86 \%$ in August and $91 \%$ during the week of the shows. Revenue shows a massive jump during the week of the concert compared with other times represented, which is in line with the high occupancy numbers of the week. Other variables follow the same pattern, given that most of them are derived from occupancy and revenues. Indeed, it is particularly jarring that the maximum values of the demand indicators during the week of the concert are also largely the maximum values across the entire sample.

Figure 3.1: Average ADR by Weekday, 2004-2018 vs. Week of Home Shows

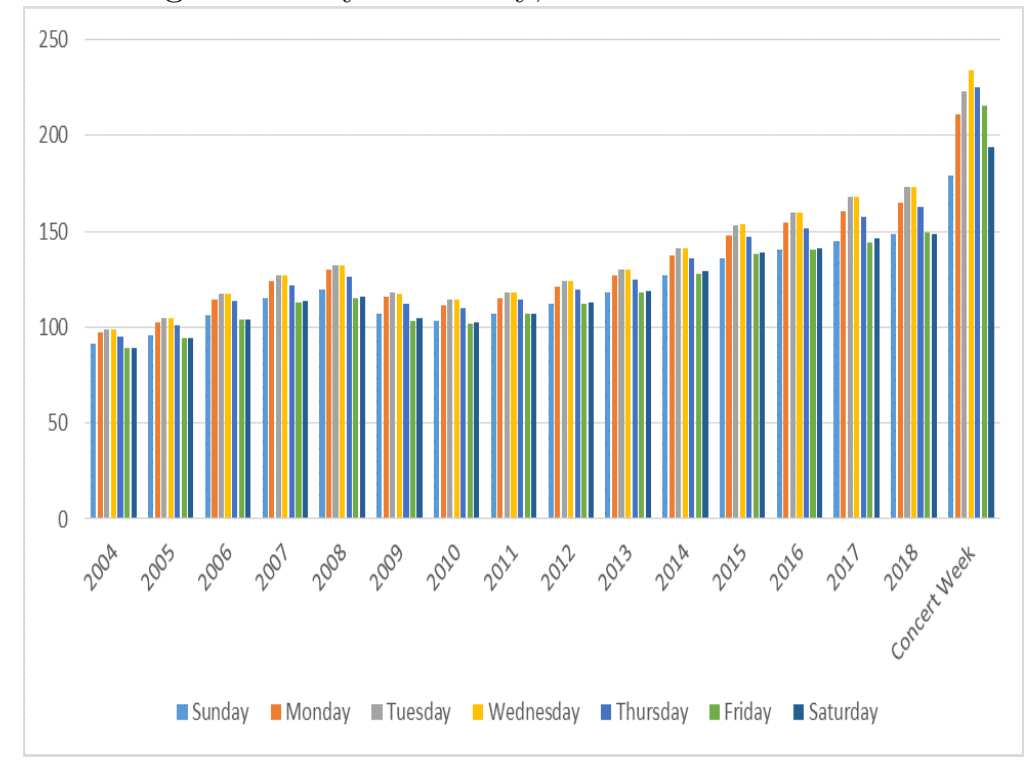

A breakdown of Average ADR by day of the week and year is given in Figure 3.1 for the full sample and Figure 3.1 for days just in August. In each graph, the ADR for the week of the concert is given, and in each case appears significantly higher than the yearly averages by day of week in the full sample, and relatively higher than daily averages in the August sample. This is especially pertinent to the 2018 number, given 
that this is the year the home shows took place. It is also in line with the summary statistics described in Table 3.1 .

Figure 3.2: Average ADR by Weekday, Aug. 2004-2018 vs. Week of Home Shows

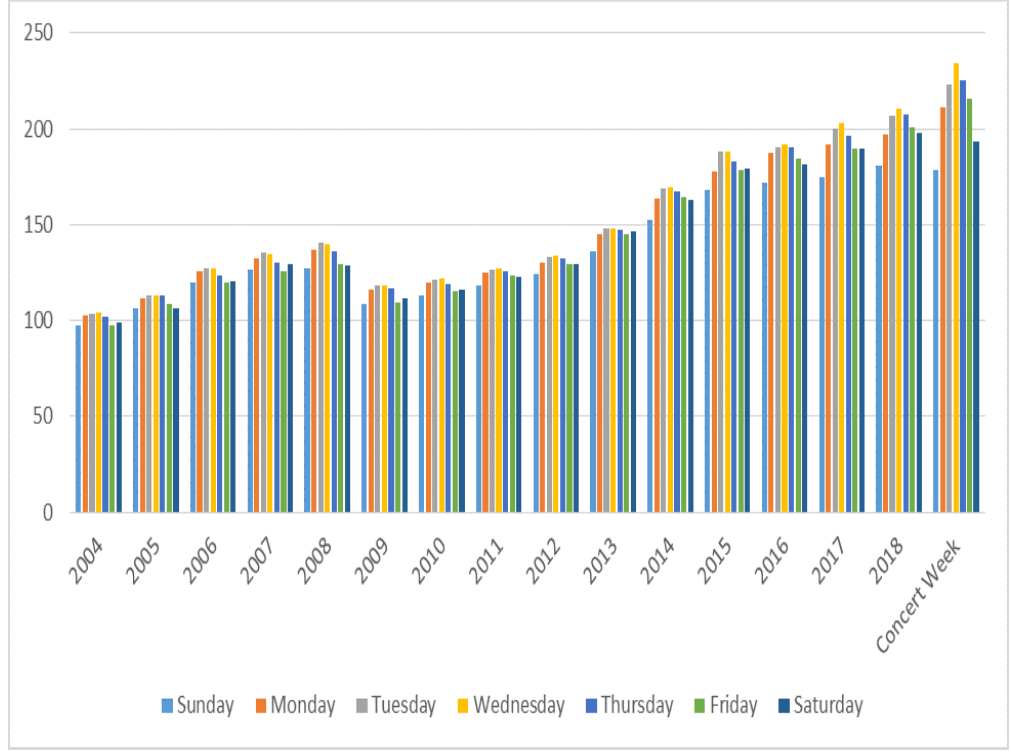

\subsection{Empirical Results}

Our analysis is conducted on five variables listed in Table 3.1: average daily room rates (ADR), revenue per available room (RevPar), demand, occupancy, and revenue (in thousands). Each specification controls for the days on which recurring major home sports games played by three major local teams-the Sounders, the Seahawks, and the Mariners-could distort hotel demand. This is accomplished with a matrix of dummy variables for each day a home game is played on. Model fixed effects are included for the day of week to control for recurrently high-demand days, the week in the total sample to control for other, non-recurrent events, the month of the year to control for seasonal demand, and the year in the sample to control for yearly trends in supply, demand, overall price increases, etc. 
These fixed effects help account for the upward trend seen in the Figures 1 and 2 , which show clear gains. It would also help to show if there's clear evidence of a difference between the week of sample observation in the figures and the 2018 numbers, both for August and for the whole sample, as "August" and "2018" are controlled for in the model. Finally, dummies are constructed for plus/minus five days before the first and after the second concert, to control for the build-up in travelers arriving for the destination event. Alongside these are controls for the days of the shows-August 8th and 10th, 2018-as well as the day falling in between the shows. The coefficients of these variables can be thought of as the average percentage Significance in all said indicator variables for the days of the concert time frame showing a build-up in the prior days, followed by a relative peak during the shows and a decline during the days following the shows, would provide evidence that the shows led to a significant increase in hotel demand during the Home shows and thus that such events bring in a large volume of outside travel and hotel spending from concert tourists.

We find statistically significant effects on hotel demand on the concert days, the day in between the concerts, and in the days both leading up to and following the concert; results reported in Table 3.2. This is consistent with the hypothesis that the Pearl Jam Home Shows were a destination event-people filled up hotel rooms for several days before and after the concert in the absence of another major event. Indeed, occupancy spiked at around $96 \%$ the day of the concert, and was in the $88 \%$ to $90 \%$ range for the day before the first show and the three days preceding the show. This also makes sense when one considers the days of the week the shows fell onWednesday August 8 and Friday August 10, 2018. People would be more likely to stay after the last show, given that it's a weekend, versus during the days preceding the first show, given that they're workdays. The trend in occupancy is also observed in $\mathrm{ADR}$, with revenue rates per room rising to over $\$ 200$ a night on the concert days, 
Table 3.2: Econometric Models

\begin{tabular}{|c|c|c|c|c|c|}
\hline & ADR & Occupancy & RevPar & Demand & Revenue \\
\hline (Intercept) & $\begin{array}{c}65.771^{* * *} \\
(3.514)\end{array}$ & $\begin{array}{c}29.187^{* * *} \\
(3.212)\end{array}$ & $\begin{array}{c}17.179^{* * *} \\
(6.114)\end{array}$ & $\begin{array}{c}10611.212^{\text {*** }} \\
(1291.798)\end{array}$ & $\begin{array}{l}610.724^{* *} \\
(259.199)\end{array}$ \\
\hline Seahawks & $\begin{array}{c}4.598^{* * *} \\
(0.553)\end{array}$ & $\begin{array}{c}5.846^{* * *} \\
(0.505)\end{array}$ & $\begin{array}{c}10.440^{* * * *} \\
(0.961)\end{array}$ & $\begin{array}{c}2362.205^{* * *} \\
(203.158)\end{array}$ & $\begin{array}{c}430.090^{* * *} \\
(40.764)\end{array}$ \\
\hline Mariners & $\begin{array}{c}1.484^{* * *} \\
(0.290)\end{array}$ & $\begin{array}{c}1.957^{* * *} \\
(0.265)\end{array}$ & $\begin{array}{c}3.538^{* * *} \\
(0.505)\end{array}$ & $\begin{array}{c}765.591^{* * *} \\
(106.617)\end{array}$ & $\begin{array}{c}140.648^{* * *} \\
(21.393)\end{array}$ \\
\hline Sounders & $\begin{array}{c}0.028 \\
(0.507)\end{array}$ & $\begin{array}{c}1.265^{* * *} \\
(0.464)\end{array}$ & $\begin{array}{c}0.741 \\
(0.883)\end{array}$ & $\begin{array}{l}456.762^{* *} \\
(186.555)\end{array}$ & $\begin{array}{c}15.654 \\
(37.432)\end{array}$ \\
\hline PlusSix & $\begin{array}{l}-7.181 \\
(7.457)\end{array}$ & $\begin{array}{l}-6.807 \\
(6.816)\end{array}$ & $\begin{array}{l}-19.932 \\
(12.974)\end{array}$ & $\begin{array}{l}-3359.625 \\
(2741.360)\end{array}$ & $\begin{array}{c}-925.225^{*} \\
(550.054)\end{array}$ \\
\hline PlusFive & $\begin{array}{l}-5.307 \\
(7.458)\end{array}$ & $\begin{array}{l}-9.065 \\
(6.817)\end{array}$ & $\begin{array}{l}-19.652 \\
(12.976)\end{array}$ & $\begin{array}{l}-4156.640 \\
(2741.817)\end{array}$ & $\begin{array}{l}-853.454 \\
(550.145)\end{array}$ \\
\hline PlusFour & $\begin{array}{l}-9.065 \\
(7.458)\end{array}$ & $\begin{array}{c}-10.654 \\
(6.817)\end{array}$ & $\begin{array}{c}-27.048^{* *} \\
(12.975)\end{array}$ & $\begin{array}{c}-4995.751^{*} \\
(2741.706)\end{array}$ & $\begin{array}{c}-1212.281^{* *} \\
(550.123)\end{array}$ \\
\hline PlusThree & $\begin{array}{c}-11.910 \\
(7.457)\end{array}$ & $\begin{array}{l}-5.501 \\
(6.817)\end{array}$ & $\begin{array}{c}-23.678^{*} \\
(12.975)\end{array}$ & $\begin{array}{l}-2985.059 \\
(2741.559)\end{array}$ & $\begin{array}{c}-1120.034^{* *} \\
(550.093)\end{array}$ \\
\hline PlusTwo & $\begin{array}{c}-16.346^{* *} \\
(7.460)\end{array}$ & $\begin{array}{l}-5.555 \\
(6.819)\end{array}$ & $\begin{array}{c}-34.376^{* * *} \\
(12.980)\end{array}$ & $\begin{array}{l}-3725.124 \\
(2742.690)\end{array}$ & $\begin{array}{c}-1749.721^{* * *} \\
(550.320)\end{array}$ \\
\hline PlusOne & $\begin{array}{c}120.539^{* * *} \\
(8.112)\end{array}$ & $\begin{array}{c}60.804^{* * *} \\
(7.415)\end{array}$ & $\begin{array}{c}148.367^{* * *} \\
(14.114)\end{array}$ & $\begin{array}{c}31149.643^{* * *} \\
(2982.384)\end{array}$ & $\begin{array}{c}7106.260^{* * *} \\
(598.415)\end{array}$ \\
\hline ConcertDays & $\begin{array}{c}144.789^{* * *} \\
(6.892)\end{array}$ & $\begin{array}{c}67.692^{* * *} \\
(6.300)\end{array}$ & $\begin{array}{c}187.486^{* * *} \\
(11.991)\end{array}$ & $\begin{array}{c}34503.705^{* * *} \\
(2533.648)\end{array}$ & $\begin{array}{c}8996.060^{* * *} \\
(508.376)\end{array}$ \\
\hline InBetw & $\begin{array}{c}138.829^{* * *} \\
(8.131)\end{array}$ & $\begin{array}{c}61.391^{* * *} \\
(7.433)\end{array}$ & $\begin{array}{c}174.288^{* * *} \\
(14.147)\end{array}$ & $\begin{array}{c}31854.211^{* * *} \\
(2989.337)\end{array}$ & $\begin{array}{c}8435.039^{* * *} \\
(599.810)\end{array}$ \\
\hline MinusOne & $\begin{array}{c}135.293^{* * *} \\
(8.136)\end{array}$ & $\begin{array}{c}65.811^{* * *} \\
(7.437)\end{array}$ & $\begin{array}{c}177.170^{* * *} \\
(14.156)\end{array}$ & $\begin{array}{c}33721.194^{* * *} \\
(2991.257)\end{array}$ & $\begin{array}{c}8557.183^{* * *} \\
(600.195)\end{array}$ \\
\hline MinusTwo & $\begin{array}{c}126.998^{* * *} \\
(8.143)\end{array}$ & $\begin{array}{c}65.470^{* * *} \\
(7.443)\end{array}$ & $\begin{array}{c}162.885^{* * *} \\
(14.167)\end{array}$ & $\begin{array}{c}33141.561^{* * *} \\
(2993.590)\end{array}$ & $\begin{array}{c}7816.936^{* * *} \\
(600.663)\end{array}$ \\
\hline MinusThree & $\begin{array}{c}121.156^{* * *} \\
(8.152)\end{array}$ & $\begin{array}{c}69.895^{* * *} \\
(7.451)\end{array}$ & $\begin{array}{c}156.877^{* * *} \\
(14.183)\end{array}$ & $\begin{array}{c}34530.739^{* * *} \\
(2996.898)\end{array}$ & $\begin{array}{c}7415.253^{* * *} \\
(601.327)\end{array}$ \\
\hline MinusFour & $\begin{array}{c}17.991^{* * *} \\
(6.896)\end{array}$ & $\begin{array}{c}6.483 \\
(6.304)\end{array}$ & $\begin{array}{l}29.915^{* *} \\
(11.999)\end{array}$ & $\begin{array}{c}3498.821 \\
(2535.320)\end{array}$ & $\begin{array}{c}1442.354^{* * *} \\
(508.712)\end{array}$ \\
\hline MinusFive & $\begin{array}{c}14.294^{* *} \\
(6.896)\end{array}$ & $\begin{array}{c}5.658 \\
(6.303)\end{array}$ & $\begin{array}{l}23.216^{*} \\
(11.998)\end{array}$ & $\begin{array}{c}3020.978 \\
(2535.156)\end{array}$ & $\begin{array}{c}1113.962^{* *} \\
(508.679)\end{array}$ \\
\hline MinusSix & $\begin{array}{l}12.320^{*} \\
(6.897)\end{array}$ & $\begin{array}{l}2.430 \\
(6.304)\end{array}$ & $\begin{array}{c}18.204 \\
(12.000)\end{array}$ & $\begin{array}{c}1620.335 \\
(2535.600)\end{array}$ & $\begin{array}{l}934.363^{*} \\
(508.768)\end{array}$ \\
\hline $\mathrm{R}^{2}$ & 0.956 & 0.887 & 0.925 & 0.910 & 0.936 \\
\hline Fixed Effects & $\checkmark$ & $\checkmark$ & $\checkmark$ & $\checkmark$ & $\checkmark$ \\
\hline
\end{tabular}

Notes: ${ }^{* * *} p<0.01,{ }^{* *} p<0.05,{ }^{*} p<0.1$. $\mathrm{N}=5,479$ for all models. The dependent variable is noted across the top of each specification. Day of the week, week, month, and year fixed effects included.

remaining in at least the high $\$ 100$ s a night from the day before the show until about five days after the show. A possible confounding factor is a clustering of pre-season football and regular season baseball games around the time of the home shows. The 
effect of this is controlled for in the model.

The summation of the significant days-of-concert variables in Table 3.2 ("Revenue" regression) yields a figure of about $\$ 58.7$ million, which can be interpreted as the additional revenue brought in over those days on top of the constant average over the whole sample, represented by the intercept. The City of Seattle has a lodging tax of 15.6 percent for hotels with more than 60 beds (Washington State Department of Revenue, 2018). ${ }^{2}$ If every additional dollar of hotel revenue occured in Seattle this amounts to an increase in hotel tax revenue of $\$ 9.15$ million. The hotel tax varies throughout King County, however, with Seattle being the maximum and the lowest being $11.4 \%$ (Washington State Department of Revenue, 2018). If every hotel night was outside Seattle proper but in King County and in a hotel with 60 or more beds, the additional hotel tax revenue from the Home Shows is at least $\$ 6.69$ million. $^{3}$

\subsection{Robustness Check}

In addition to the regression results reported in Table 3.2, results are also reported for a set of placebo regressions in Table 3.3. The function of the placebo regressions in this particular incidence is to see whether or not assuming that the Home Shows took place on the same days in a random year produce results similar to the regressions for the Home Shows. The placebo dates in this case are August 8 and 10, 2015.

The means (intercepts) are essentially the same for every variable of interest across

\footnotetext{
${ }^{2}$ Seattle also has a tourism improvement area downtown. The seventy hotels in downtown Seattle with more than 60 beds levy an additional $\$ 2$ per occupied room, per night. We ignore this $\$ 2$ tax in our analysis, but it could be as high a few hundred thousands, depending on how many Pearl Jam funds crowded non-Pearl Jam hotel customers to outlying areas.

${ }^{3}$ While our hotel data includes hotels in the entire Seattle Metropolitan area, cities in Snohomish and Pierce counties have hotel taxes consistent with the areas of King County that are not Seattle proper (Washington State Department of Revenue, 2018). For this reason we feel confident in saying that the Home Shows brought at least $\$ 6.69$ million in additional tax revenue to city governments in the Seattle metropolitan area.
} 
Table 3.3: Placebo Models

\begin{tabular}{|c|c|c|c|c|c|}
\hline & ADR & Occupancy & RevPar & Demand & Revenue \\
\hline (Intercept) & $\begin{array}{c}65.769^{* * *} \\
(3.518)\end{array}$ & $\begin{array}{c}29.191^{* * *} \\
(3.213)\end{array}$ & $\begin{array}{c}17.182^{* * *} \\
(6.125)\end{array}$ & $\begin{array}{c}10612.869^{* * *} \\
(1292.552)\end{array}$ & $\begin{array}{l}610.836^{* *} \\
(259.872)\end{array}$ \\
\hline Seahawks & $\begin{array}{c}4.591^{* * *} \\
(0.554)\end{array}$ & $\begin{array}{c}5.861^{* * *} \\
(0.506)\end{array}$ & $\begin{array}{c}10.456^{* * *} \\
(0.964)\end{array}$ & $\begin{array}{c}2368.509^{* * * *} \\
(203.434)\end{array}$ & $\begin{array}{c}430.796^{* * *} \\
(40.901)\end{array}$ \\
\hline Mariners & $\begin{array}{c}1.488^{* * *} \\
(0.290)\end{array}$ & $\begin{array}{c}1.982^{* * *} \\
(0.265)\end{array}$ & $\begin{array}{c}3.585^{* * *} \\
(0.505)\end{array}$ & $\begin{array}{c}778.301^{* * *} \\
(106.659)\end{array}$ & $\begin{array}{c}143.005^{* * *} \\
(21.444)\end{array}$ \\
\hline Sounders & $\begin{array}{l}-0.025 \\
(0.507)\end{array}$ & $\begin{array}{c}1.276^{* * *} \\
(0.463)\end{array}$ & $\begin{array}{c}0.669 \\
(0.882)\end{array}$ & $\begin{array}{l}456.475^{* *} \\
(186.227)\end{array}$ & $\begin{array}{c}11.351 \\
(37.442)\end{array}$ \\
\hline PlusSixPlacebo & $\begin{array}{l}-1.552 \\
(1.903)\end{array}$ & $\begin{array}{l}-0.848 \\
(1.738)\end{array}$ & $\begin{array}{l}-2.667 \\
(3.314)\end{array}$ & $\begin{array}{l}-374.881 \\
(699.319)\end{array}$ & $\begin{array}{l}-113.170 \\
(140.601)\end{array}$ \\
\hline PlusFivePlacebo & $\begin{array}{l}-1.127 \\
(1.933)\end{array}$ & $\begin{array}{l}-0.787 \\
(1.766)\end{array}$ & $\begin{array}{l}-2.240 \\
(3.366)\end{array}$ & $\begin{array}{l}-321.133 \\
(710.317)\end{array}$ & $\begin{array}{l}-93.169 \\
(142.812)\end{array}$ \\
\hline PlusFourPlacebo & $\begin{array}{l}-2.379 \\
(1.950)\end{array}$ & $\begin{array}{l}-1.013 \\
(1.781)\end{array}$ & $\begin{array}{l}-4.321 \\
(3.395)\end{array}$ & $\begin{array}{l}-426.134 \\
(716.577)\end{array}$ & $\begin{array}{l}-180.461 \\
(144.070)\end{array}$ \\
\hline PlusThreePlacebo & $\begin{array}{l}-1.362 \\
(1.953)\end{array}$ & $\begin{array}{l}-0.635 \\
(1.784)\end{array}$ & $\begin{array}{l}-3.128 \\
(3.400)\end{array}$ & $\begin{array}{l}-305.237 \\
(717.571)\end{array}$ & $\begin{array}{l}-140.307 \\
(144.270)\end{array}$ \\
\hline PlusTwoPlacebo & $\begin{array}{c}0.226 \\
(1.943)\end{array}$ & $\begin{array}{l}-1.660 \\
(1.774)\end{array}$ & $\begin{array}{l}-1.751 \\
(3.382)\end{array}$ & $\begin{array}{l}-638.127 \\
(713.731)\end{array}$ & $\begin{array}{c}-63.314 \\
(143.498)\end{array}$ \\
\hline PlusOnePlacebo & $\begin{array}{l}-0.762 \\
(1.923)\end{array}$ & $\begin{array}{l}-1.466 \\
(1.756)\end{array}$ & $\begin{array}{l}-2.659 \\
(3.347)\end{array}$ & $\begin{array}{l}-596.770 \\
(706.423)\end{array}$ & $\begin{array}{l}-109.082 \\
(142.029)\end{array}$ \\
\hline ConcertDays & $\begin{array}{c}18.804^{* * *} \\
(5.274)\end{array}$ & $\begin{array}{c}2.202 \\
(4.817)\end{array}$ & $\begin{array}{c}26.180^{* * *} \\
(9.182)\end{array}$ & $\begin{array}{c}1370.378 \\
(1937.793)\end{array}$ & $\begin{array}{c}1272.994^{* * *} \\
(389.601)\end{array}$ \\
\hline InBetw & $\begin{array}{l}12.842^{*} \\
(6.832)\end{array}$ & $\begin{array}{l}-4.112 \\
(6.239)\end{array}$ & $\begin{array}{c}12.958 \\
(11.893)\end{array}$ & $\begin{array}{l}-1285.280 \\
(2510.001)\end{array}$ & $\begin{array}{c}710.815 \\
(504.645)\end{array}$ \\
\hline MinusOnePlacebo & $\begin{array}{l}-1.388 \\
(1.951)\end{array}$ & $\begin{array}{c}1.333 \\
(1.782)\end{array}$ & $\begin{array}{l}-0.655 \\
(3.397)\end{array}$ & $\begin{array}{c}476.595 \\
(716.942)\end{array}$ & $\begin{array}{c}-45.994 \\
(144.144)\end{array}$ \\
\hline MinusTwoPlacebo & $\begin{array}{l}-2.113 \\
(1.989)\end{array}$ & $\begin{array}{c}1.864 \\
(1.817)\end{array}$ & $\begin{array}{l}-0.736 \\
(3.463)\end{array}$ & $\begin{array}{c}654.906 \\
(730.935)\end{array}$ & $\begin{array}{c}-57.432 \\
(146.957)\end{array}$ \\
\hline MinusThreePlacebo & $\begin{array}{l}-1.338 \\
(2.026)\end{array}$ & $\begin{array}{l}1.794 \\
(1.850)\end{array}$ & $\begin{array}{l}0.723 \\
(3.527)\end{array}$ & $\begin{array}{c}675.033 \\
(744.347)\end{array}$ & $\begin{array}{c}13.795 \\
(149.654)\end{array}$ \\
\hline MinusFourPlacebo & $\begin{array}{l}-2.587 \\
(2.059)\end{array}$ & $\begin{array}{l}1.426 \\
(1.880)\end{array}$ & $\begin{array}{l}-1.295 \\
(3.584)\end{array}$ & $\begin{array}{c}487.370 \\
(756.485)\end{array}$ & $\begin{array}{c}-76.804 \\
(152.094)\end{array}$ \\
\hline MinusFivePlacebo & $\begin{array}{l}-3.135 \\
(2.074)\end{array}$ & $\begin{array}{c}0.885 \\
(1.894)\end{array}$ & $\begin{array}{l}-2.574 \\
(3.610)\end{array}$ & $\begin{array}{c}284.974 \\
(761.950)\end{array}$ & $\begin{array}{l}-123.174 \\
(153.193)\end{array}$ \\
\hline MinusSixPlacebo & $\begin{array}{c}-5.227^{* *} \\
(2.095)\end{array}$ & $\begin{array}{l}-0.638 \\
(1.913)\end{array}$ & $\begin{array}{c}-6.445^{*} \\
(3.647)\end{array}$ & $\begin{array}{l}-343.279 \\
(769.675)\end{array}$ & $\begin{array}{c}-286.195^{*} \\
(154.746)\end{array}$ \\
\hline $\mathrm{R}^{2}$ (full sample) & 0.948 & 0.867 & 0.911 & 0.894 & 0.924 \\
\hline Fixed Effects & $\checkmark$ & $\checkmark$ & $\checkmark$ & $\checkmark$ & $\checkmark$ \\
\hline
\end{tabular}

Notes: ${ }^{* * *} p<0.01,{ }^{* *} p<0.05,{ }^{*} p<0.1$. $\mathrm{N}=5,479$ for all models. The dependent variable is noted across the top of each specification. Day of the week, week, month, and year fixed effects included.

both tables; however, the day indicator variables for the time of the concert placebo largely fail to test significant across all specifications. There is some evidence of higher ADR to the level of $\$ 84$ during the concert days, perhaps picking up some of 
the effect of a Mariners game played on the 10th, or another event not captured in this model. Still, the lack of any evidence in favor of higher demand on days leading up to, in between, and following the concert provide evidence that the results of Table 3.2 were unique to those particular occurrences of August 8th and 10th in 2018, when the Home Shows took place.

\subsection{Conclusion}

Cities frequently tout mega events such as the Super Bowl as vehicles for economic growth (Coates \& Depken, 2011; Coates \& Humphreys, 2002). While the literature is clear that the benefits from mega events are not enough to justify public subsidies (Coates \& Humphreys, 2008; B. Humphreys et al., 2019), that does not mean that mega events do not sometimes have positive economic impacts. Rather, the argument is that the consumption and income benefits of the mega event do not justify the investment of public dollars.

In this paper we estimate the impact of Pearl Jam's "Home Shows" on hotel demand. We find, unlike other hotel demand papers related to sports, significant leads, indicating many fans came for multiple days. Over the range of statistically significant days in early August 2018, we find that the Pearl Jam Home Shows increased average daily room rates by as much as $\$ 144$ a night and hotel occupancy to over $90 \%$. The increase in hotel revenue attributed to the Home Shows is over $\$ 58$ million. Depending upon assumptions about the localities fans were located in, we estimated that the additional hotel tax revenue brought in to Seattle metro-area municipalities is between $\$ 6.69$ million and $\$ 9.15$ million.

Given the unique nature of Pearl Jam the band (each concert is unique), their ticket distribution system, the limited touring schedule around in 2017 and 2018, 
etc., we argue that this case presents an upper bound of what a mega event can have on hotel demand. Even if food, beverage, and entertainment purchases by Pearl Jam fans while in Seattle entirely crowded out purchases by residents, the economic impact of the Home Shows on the Seattle economy was substantial. 


\title{
Bibliography
}

\author{
41 FCC 148. (1952).
}

Ahlfeldt, G., \& Maennig, W. (2009). Arenas, arena architecture and the impact on location desirability: The case of 'olympic arenas in prenzlauer berg, berlin. Urban Studies, 46(7), 1343-1362. doi: 10.1177/0042098009104569

Albouy, D., Graf, W., Kellogg, R., \& Wolff, H. (2016). Climate amenities, climate change, and american quality of life. Journal of the Association of Environmental and Resource Economists, 3(1), 205 - 246. Retrieved from http://www . libproxy . wvu . edu/login?url=http://search. ebscohost . com/login . aspx?direct=true\&db=ecn\&AN=1665783

Anderson, J. E. (2005). Casino taxation in the united states. National Tax Journal, $58(2), 303-324$.

Anonymous. (1951). The impact of the fccs chain broadcasting rules. The Yale Law Journal, 60(1), 78-111. doi: 10.2307/793633

Anonymous. (1987, Apr). Fox broadcasting co.: The birth of a network. Broadcasting, 88-90.

Baade, R. A., \& Matheson, V. A. (2001). Home run or wild pitch? Assessing the economic impact of Major League Baseball's All-Star Game. Journal of Sports Economics, 2(4), 307-327.

Becker, G. S. (1968). Crime and punishment: an economic approach. The Economic Dimensions of Crime, 13-68. doi: 10.1007/978-1-349-62853-7_2

Besen, S. M. (1986). Misregulating television: network dominance and the fcc. The University of Chicago Press.

Bin, O., Kruse, J. B., \& Landry, C. E. (2008). Flood hazards, insurance rates, and amenities: Evidence from the coastal housing market. Journal of Risk and Insurance, 75(1), 63 - 82. Retrieved from http://www. libproxy.wvu.edu/login?url=http://search. ebscohost . com/login . aspx?direct $=$ true\&db=ecn\&AN=0963766

Boehlert, E. (1995). Pearl Jam: Taking on Ticketmaster. Rolling Stone, 28 December.

Boggess, L. N., Greenbaum, R. T., \& Tita, G. E. (2013). Does crime drive housing sales? evidence from los angeles. Journal of Crime and Justice, 36 (3), 299-318. doi: $10.1080 / 0735648 x .2013 .812976$ 
Bonneau, D., \& Hall, J. (2020). The impact of WVU football and basketball on hotel demand. New York Economic Review, forthcoming.

Borgoni, R., Michelangeli, A., \& Pontarollo, N. (2018). The value of culture to urban housing markets. Regional Studies, 52(12), 1672 - 1683. Retrieved from http://www. libproxy.wvu.edu/login?url=http://search. ebscohost .com/login . aspx?direct =true\&db=ecn\&AN=1739380

Bracalente, B., Chirieleison, C., Cossignani, M., Ferrucci, L., Gigliotti, M., \& Ranalli, M. G. (2011). The economic impact of cultural events: The Umbria Jazz music festival. Tourism Economics, 17(6), 1235-1255.

Brandt, S., Maennig, W., \& Richter, F. (2014). Do houses of worship affect housing prices? evidence from germany. Growth and Change, 45(4), 549 - 570. Retrieved from http://www. libproxy.wvu.edu/login?url=http://search. ebscohost .com/login . aspx?direct $=$ true\&db=ecn\&AN=1505525

Bray, W. J. (1965). Satellite communication systems. Physics Bulletin, 16(12), 470-476. doi: 10.1088/0031-9112/16/12/001

Broadcasting Publications. (1987). Broadcasting cable yearbook.

Brooks, T., \& Marsh, E. (1999). The complete directory to prime time network and cable tv shows 1946 - present. Ballantine Books.

Case, B., \& Quigley, J. M. (1991). The dynamics of real estate prices. The Review of Economics and Statistics, 73(1), 50. doi: 10.2307/2109686

Coates, D., \& Depken, C. A. (2011). Mega-events: Is Baylor football to Waco what the Super Bowl is to Houston? Journal of Sports Economics, 12(6), 599-620.

Coates, D., \& Humphreys, B. R. (2002). The economic impact of postseason play in professional sports. Journal of Sports Economics, 3(3), 291-299.

Coates, D., \& Humphreys, B. R. (2008). Do economists reach a conclusion on subsidies for sports franchises, stadiums, and mega-events? Econ Journal Watch, 5(3), 294-315.

Collins, C., Depken, C., \& Stephenson, E. F. (2020). The impact of sporting and cultural events in a heterogeneous hotel market: Evidence from Austin, TX. Berry College Working Paper.

Cox, D. R. (1972). Regression models and life-tables. Journal of the Royal Statistical Society: Series B (Methodological), 34(2), 187-202. doi: 10.1111/j.2517-6161 .1972.tb00899.x

Cox, K. R. (2016). The politics of urban and regional development and the american exception. Syracuse University Press.

Crandall, R. W. (1974). The economic ease for a fourth commercial television network. Public Policy, 22, 513-536. doi: 10.1086/466715

Crompton, J. L., Lee, S., \& Shuster, T. J. (2001). A guide for undertaking economic impact studies: The Springfest example. Journal of Travel Research, 40(1), 79-87.

Depken, C. A., \& Stephenson, E. F. (2018). Hotel demand before, during, and after sports events: Evidence from Charlotte, North Carolina. Economic Inquiry, 
$56(3), 1764-1776$.

De Vany, A. (2008). The market for motion pictures: Revenue, rank, and survival. In Hollywood economics: How extreme uncertainty shapes the film industry (p. 11-27). Routledge.

Dobson, A. J., \& Barnett, A. G. (2018). An introduction to generalized linear models. CRC Press, Taylor \& Francis Group.

Earhart, M., \& Stephenson, E. F. (2018). Same-sex marriage legalization and wedding tourism: Evidence from Charleston and Savannah. Journal of Economics and Finance, 42(3), 566-574.

Ehrlich, I. (1973). Participation in illegitimate activities: A theoretical and empirical investigation. Journal of Political Economy, 81(3), 521-565. doi: 10.1086/ 260058

FCC Network Inquiry Special Staff. (1980). New television networks: Entry, jurisdiction, ownership and regulation (vol. 1 and 2).

Federal Communications Commission. (1972). Domestic Communication-Satellite Facilities by Non-Governmental Entities. 35 FCC 2d 844.

Fortin, N. M., Hill, A. J., \& Huang, J. (2014). Superstition in the housing market. Economic Inquiry, 52(3), 974 - $993 . \quad$ Retrieved from http://www.libproxy . wvu. edu/login?url=http://search. ebscohost .com/login . aspx?direct $=$ true\&db $=$ ecn\&AN $=1453770$

Franco, S. F., \& Macdonald, J. L. (2018). The effects of cultural heritage on residential property values: Evidence from lisbon, portugal. Regional Science and Urban Economics, 70, 35 - 56. Retrieved from http://www.libproxy.wvu.edu/login?url=http://search. ebscohost .com/login . aspx?direct $=$ true\&db=ecn\&AN $=1717447$

Gabe, T. (2016). I would walk 500 miles: Using travel costs to analyse the market for popular music concerts. Applied Economics Letters, 23(13), 949-952.

Gabe, T. M., \& Lisac, N. A. (2014). A note on the effects of popular music concerts on hospitality sales: The case of waterfront concerts in Bangor, Maine. Review of Regional Studies, 44(1), 61-74.

Garrett, T. A. (2004). Casino gaming and local employment trends. ICPSR Data Holdings. doi: 10.3886/icpsr01297

Gazel, R. C., \& Schwer, R. K. (1997). Beyond rock and roll: The economic impact of the Grateful Dead on a local economy. Journal of Cultural Economics, 21(1), $41-55$.

Grinols, E. L., Mustard, D. B., \& Dilley, C. H. (2006, Feb). Casinos, crime and community costs. The Review of Economics and Statistics, 88(1), 28-45. doi: $10.2139 / \operatorname{ssrn} .233792$

Hains, T. (2016). Trump proposes "new deal for black america" in charlotte. Retrieved from https://www.realclearpolitics.com/video/2016/10/ 26/trump_proposes_new_deal_for_black_america_in_charlotte.html

Heldenfels, R. D. (1994). Televisions greatest year, 1954. Continuum. 
Heller, L. R., Matheson, V. A., \& Stephenson, E. F. (2018). Unconventional wisdom: Estimating the economic impact of the Democratic and Republican national political conventions. Papers in Regional Science, 97(4), 1267-1278.

Henry, M., Mahathey, A., Morrill, T., Robinson, A., Shivji, A., \& Watt, R. (2018). The 2018 annual homeless assessment report to congress. Washington DC: US Department of Housing and Urban Development.

Hicks, R. L., \& Queen, B. M. (2016). Valuing historical and open space amenities with hedonic property valuation models. Agricultural and Resource Economics Review, 45(1), 44 - 67. Retrieved from http://www.libproxy . wvu. edu/login?url=http://search.ebscohost .com/login . aspx?direct=true\&db=ecn\&AN=1630635

Hodur, N. M., Bangsund, D. A., Leistritz, F. L., \& Kaatz, J. (2006). Estimating the contribution of a multi-purpose event facility to the area economy. Tourism Economics, 12(2), 303-316.

Humphreys, B., et al. (2019). Should the construction of new professional sports facilities be subsidized. Journal of Policy Analysis and Management, 38(1), 264-270.

Humphreys, B., \& Zhou, L. (2013, April). Sports Facilities, Agglomeration, and Urban Redevelopment (Working Papers No. 2013-4). University of Alberta, Department of Economics. Retrieved from https://ideas.repec.org/p/ris/ albaec/2013_004.html

Humphreys, B. R., \& Nowak, A. (2017). Professional sports facilities, teams and property values: Evidence from nba team departures. Regional Science and Urban Economics, 66, 39-51. doi: 10.1016/j.regsciurbeco.2017.06.001

Iams, P., Alex; Kaplan. (2006, Aug). Economic development and smart growth. International Economic Development Council.

Ihlanfeldt, K., \& Mayock, T. (2010). Panel data estimates of the effects of different types of crime on housing prices. Regional Science and Urban Economics, 40(23), 161-172. doi: 10.1016/j.regsciurbeco.2010.02.005

Jones, C. (2010). House price measurement: The hybrid hedonic repeat-sales method. Economic Record, 86(272), 95-97. doi: 10.1111/j.1475-4932.2009.00596.x

Kim, M.-K., Pang, A., Bao, W., \& Bosworth, R. (2016). Endogeneity in casino revenue and crime rates: The case of las vegas, nevada. Review of Regional Studies, 46(3), 223 - $236 . \quad$ Retrieved from http://www.libproxy. wvu. edu/login?url=http://search. ebscohost .com/login . aspx?direct=true\&db=ecn\&AN=1649830

Kleinbaum, D. G., \& Klein, M. (2012). Survival analysis: A self-learning text (3rd ed.). Springer.

Kreps, D. (2018). Pearl Jam announce Seattle stadium 'Home Shows' to fight homelessness. Rolling Stone, 22 January.

Krouoderova, D. (2018). The home shows effect: 90+ Seattle organizations join Pearl Jam to raise millions to fight homelessness. Seattle Magazine, 27 November. 
Land, T. (2018). Pearl jam raising $\$ 11$ million to fight homelessness: So where does the money go? K5 News, 8 August.

Lim, S. H., \& Zhang, L. (2016). Does casino development have a positive effect on economic growth? Growth and Change, 48(3), 409-434. doi: 10.1111/ grow.12182

Linden, L., \& Rockoff, J. E. (2008). Estimates of the impact of crime risk on property values from megans laws. American Economic Review, 98(3), 1103-1127. doi: 10.1257/aer.98.3.1103

Litman, B. R. (1979). The vertical structure of the television broadcasting industry: the coalescence of power. MSU Business Studies.

Maddison, D., \& Bigano, A. (2003). The amenity value of the italian climate. Journal of Environmental Economics and Management, 45(2), 319 - 332. Retrieved from http://www. libproxy.wvu.edu/login?url=http://search. ebscohost . com/login . aspx?direct =true\&db=ecn\&AN=0642699

Madhusudhan, R. G. (1996). Betting on casino revenues: Lessons from state experiences. National Tax Journal, $49(3), 401-412$.

Mahoney, W. (1987, Oct). How sly has fox been? Electronic Media, 1-59.

Manning, A. (2012, Dec). Crime jumps around casino. The Columbus Dispatch. Retrieved from https://www.dispatch.com/article/20121203/news/ 312039793

Mason, P. M., \& Stranahan, H. (1996). The effects of casino gambling on state tax revenue. Atlantic Economic Journal, 24(4), 336-348. doi: 10.1007/bf02298435

McNair, C. (2017). Us ad spending: emarketer's updated estimates and forecast for 2017. eMarketer. Retrieved from https ://www . emarketer. com/Report/US-Ad -Spending-eMarketers-Updated-Estimates-Forecast-2017/2002134

Meier, H., \& Rehdanz, K. (2017). The amenity value of the british climate. Urban Studies, 54(5), 1235 - 1262. Retrieved from http:// www.libproxy.wvu.edu/login?url=http://search.ebscohost.com/ login aspx?direct=true\&db=ecn\&AN=1643399

Millman, Z. (2018). 27 years later with two home shows, Pearl Jam is still the band that cares. SeattlePI, 9 August.

Munks, J., \& Petrella, D. (2019, Jun). Gov. j.b. pritzker signs bills that ignite $\$ 45$ billion construction program, massive gambling expansion and doubling of gas tax. The Chicago Tribune. Retrieved from https://www.chicagotribune.com/ politics/ct-jb-pritzker-gambling-construction-bills-gas-tax -signed-20190628-inux5umelbew je5zzdrpphz3ze-story .html

Nelson, J. P. (1978). Residential choice, hedonic prices, and the demand for urban air quality. Journal of Urban Economics, 5(3), 357-369. doi: 10.1016/0094 $-1190(78) 90016-5$

OH Revised Code Title 57:5753.01-5753.10. (2010). Chapter 5753: Casinos. Retrieved from http://codes.ohio.gov/orc/5753

Parsons, P. (2008). Blue skies: A history of cable television. Temple Univ. Press. 
Paybarah, A. (2019, Mar). Hudson yards: The making of a $\$ 25$ billion neighborhood. The New York Times.

Pearl Jam. (2011). Pearl jam twenty. New York: Simon and Schuster.

Pope, J. C. (2008). Fear of crime and housing prices: Household reactions to sex offender registries. Journal of Urban Economics, 64(3), 601-614. doi: 10.1016/ j.jue.2008.07.001

Raya, J. M., Montolio, D., \& Buonanno, P. (2012, 08). Housing prices and crime perception. Empirical Economics, 45. doi: 10.1007/s00181-012-0624-y

Recording Industry Association of America. (2020). Gold $\mathscr{6}$ platinum: Top artists (albums). Washington DC: Recording Industry Association of America.

Reece, W. S. (2010). Casinos, hotels, and crime. Contemporary Economic Policy, 28(2), 145-161. doi: 10.1111/j.1465-7287.2009.00172.x

Rehdanz, K., \& Maddison, D. (2009). The amenity value of climate to households in germany. Oxford Economic Papers, 61(1), 150 - 167. Retrieved from http://www.libproxy. wvu.edu/login?url=http://search. ebscohost .com/login . aspx?direct $=$ true\&db=ecn\&AN $=1017422$

Ries, J., \& Somerville, T. (2010). School quality and residential property values: Evidence from vancouver rezoning. Review of Economics and Statistics, 92(4), 928 - 944. Retrieved from http://www.libproxy.wvu.edu/login?url=http:// search. ebscohost. com/login . aspx?direct $=$ true\&db=ecn\&AN=1149479

Roback, J. (1982). Wages, rents, and the quality of life. Journal of Political Economy, 90 (6), 1257-1278. doi: 10.1086/261120

Rolling Stone. (2011). Rolling Stone readers pick the top ten live acts of all time. Rolling Stone, 9 March.

Rolling Stone. (2013). The new immortals: 14 more artists who will stand the test of time, from Kanye West to Wilco. Rolling Stone, 5 March.

Rosen, S. (1974). Hedonic prices and implicit markets: Product differentiation in pure competition. Journal of Political Economy, 82(1), 34-55. doi: 10.1086/260169

Ross, J. M., Farmer, M. C., \& Lipscomb, C. A. (2009, Mar). Inconsistency in welfare inferences from distance variables in hedonic regressions. The Journal of Real Estate Finance and Economics, 43(3), 385-400. doi: 10.1007/s11146-009-9221 $-\mathrm{Z}$

Rossi-Hansberg, E. A., Sarte, P.-D. G., \& Owens, R. E. (2008). Housing externalities: Evidence from spatially concentrated urban revitalization programs. SSRN Electronic Journal. doi: 10.2139/ssrn.2187909

Senior, G., \& Danson, M. (1998). Liam and Noel in Balloch: An economic impact assessment. Tourism Economics, 4(3), 265-277.

Shafer, D. (2018). Pearl Jam's 'Home Shows': Two Safeco Field concerts, millions of dollars to fight homelessness in seattle. Seattle Magazine, 27 November.

Sheehan, K., \& Stephenson, E. F. (2020). Would Columbus miss the Crew? Major League Soccer and hotel occupancy. New York Economic Review, forthcoming.

Smith, S. B. (1985, Oct). New tv technologies alter viewing habits. The New York 
Times.

The Cable Center. (2015). The cable history timeline.

Thomas, L., \& Litman, B. R. (1991). Fox broadcasting company, why now? an economic study of the rise of the fourth broadcast "network". Journal of Broadcasting \&f Electronic Media, 35(2), 139-157. doi: 10.1080/08838159109364113

Thompson, E., Butters, R. B., \& Schmitz, B. T. (2012). The property value premium of a place of worship. Contemporary Economic Policy, 30(2), 215 - 222. Retrieved from http://www.libproxy.wvu.edu/login?url=http:// search. ebscohost. com/login. aspx?direct=true\&db=ecn\&AN=1301173

Thusi, I. I. (2017, Mar). Despite claims by sessions and trump, 'broken windows' policing is broken. TheHill. Retrieved from https://thehill.com/blogs/ pundits-blog/crime/324363-despite-sessions-and-trumps-claims -broken-windows-policing-is-broken

Timmins, C. (2007). If you cannot take the heat, get out of the cerrado...recovering the equilibrium amenity cost of nonmarginal climate change in brazil. Journal of Regional Science, $47(1), 1$ - 25. Retrieved from http://www. libproxy.wvu.edu/login?url=http://search.ebscohost . com/login . aspx?direct $=$ true\&db $=$ ecn\&AN=0903165

Tu, C. C. (2005). How does a new sports stadium affect housing values? the case of fedex field. Land Economics, 81(3), 379-395. doi: 10.3368/le.81.3.379

US Space Objects Registry. (2013). 1962-alpha epsilon 1.

van Duijn, M., \& Rouwendal, J. (2013). Cultural heritage and the location choice of dutch households in a residential sorting model. Journal of Economic Geography, 13(3), 473 - 500. Retrieved from http:// www.libproxy.wvu.edu/login?url=http://search.ebscohost.com/ login aspx?direct=true\&db=ecn\&AN=1374733

Varian, H. R. (2009). Intermediate microeconomics: a modern approach. W.W. Norton \& Company.

Washington State Department of Revenue. (2018). Lodging information rates and changes: Effective july 1 - september 30, 2018. Olympia: Washington State Department of Revenue.

Weglarz, K. (2016). Pearl Jam: The conscience of arena rock. In Political rock (pp. 203-224). Routledge.

Weinstein, D. (2006). The forgotten network: Dumont and the birth of american television. Temple University Press.

Wiley, J. A., \& Walker, D. M. (2011). Casino revenues and retail property values: The detroit case. Journal of Real Estate Finance and Economics, 42(1), 99 - 114. Retrieved from http://www.libproxy.wvu.edu/login?url=http:// search. ebscohost. com/login. aspx?direct=true\&db=ecn\&AN=1244711

Wilson, J. Q., \& Kelling, G. L. (1982, Mar). Broken windows: The police and neighborhood safety. The Atlantic Monthly Group.

Yarm, M. (2011). Everybody loves our town: An oral history of grunge. New York: 
Crown Publishing. 


\section{Appendix}

Figure 3.3: Model 1 Kaplan-Meyer Survival Curve, NBC

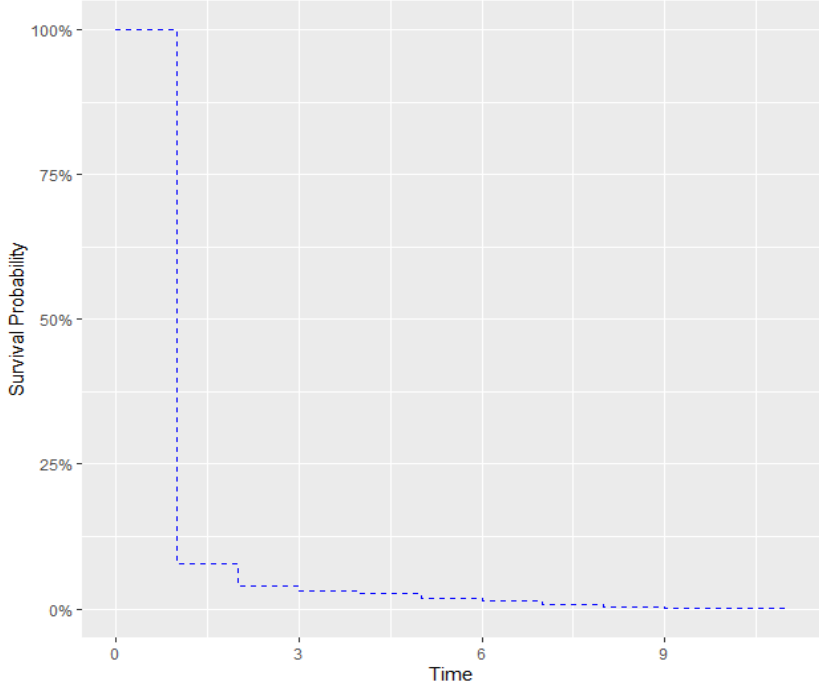


Figure 3.4: Model 2 Kaplan-Meyer Survival Curve, NBC

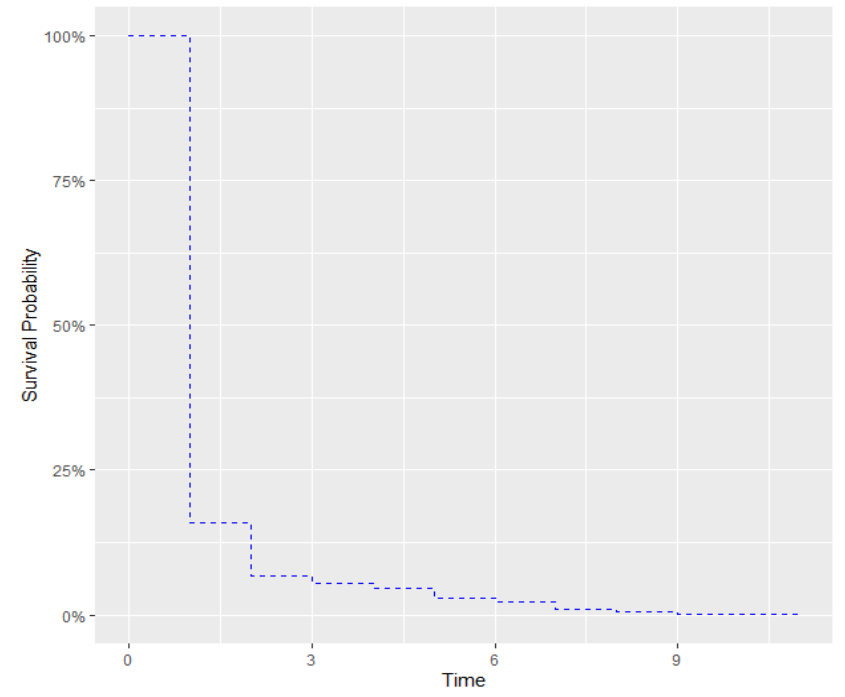

Figure 3.5: Model 3 Kaplan-Meyer Survival Curve, ABC

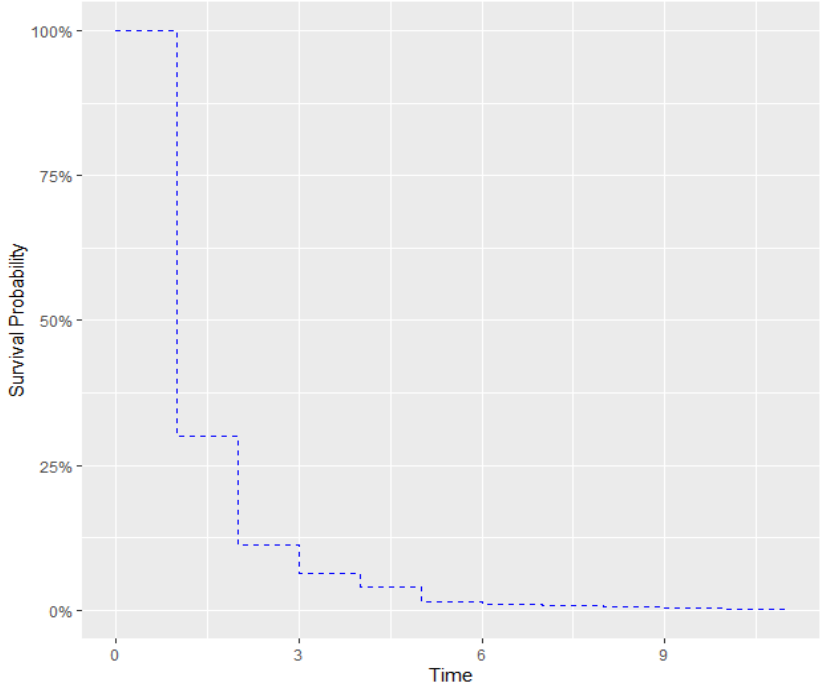


Figure 3.6: Model 4 Kaplan-Meyer Survival Curve, ABC

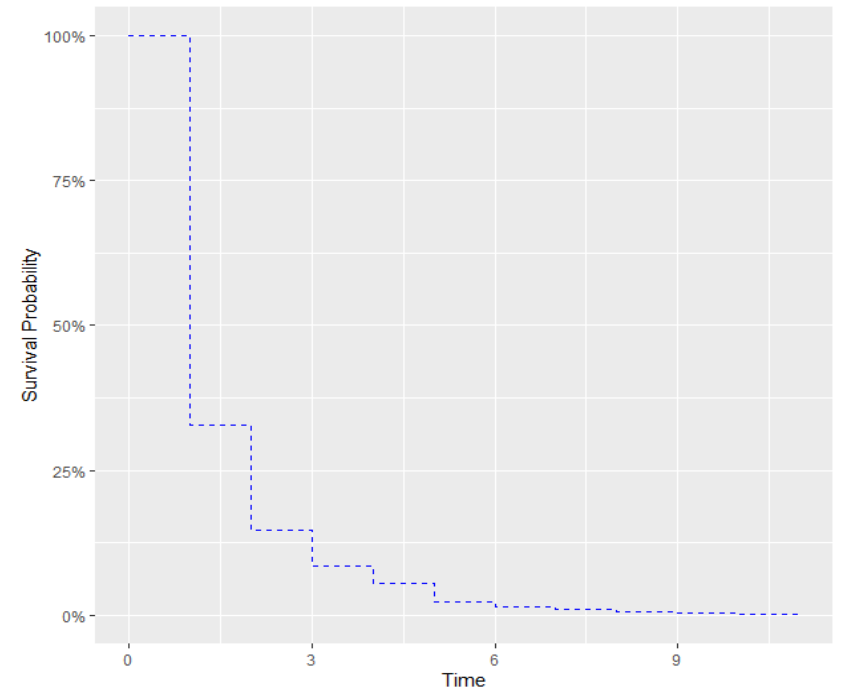

Figure 3.7: Model 5 Kaplan-Meyer Survival Curve, CBS

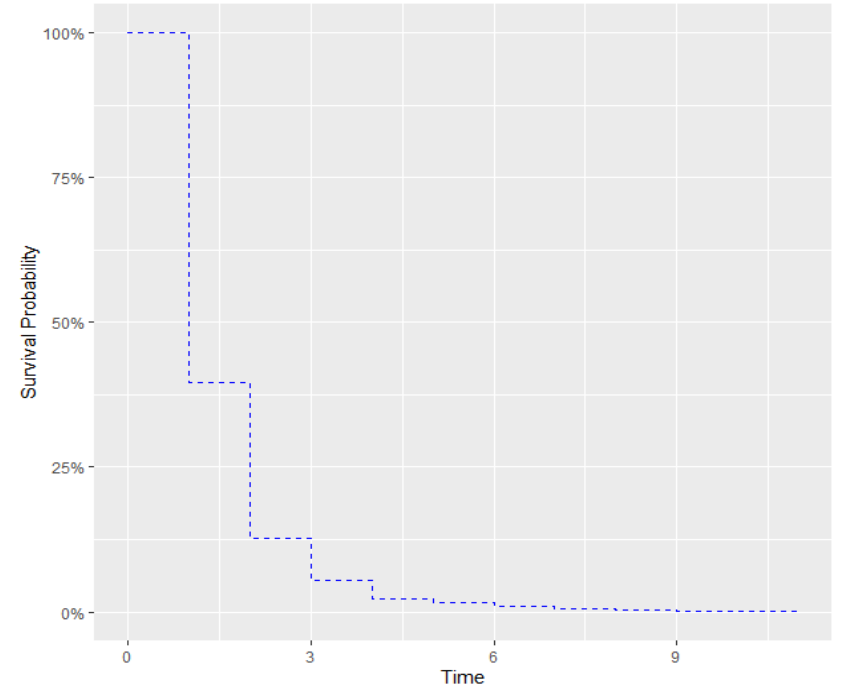


Figure 3.8: Model 6 Kaplan-Meyer Survival Curve, CBS

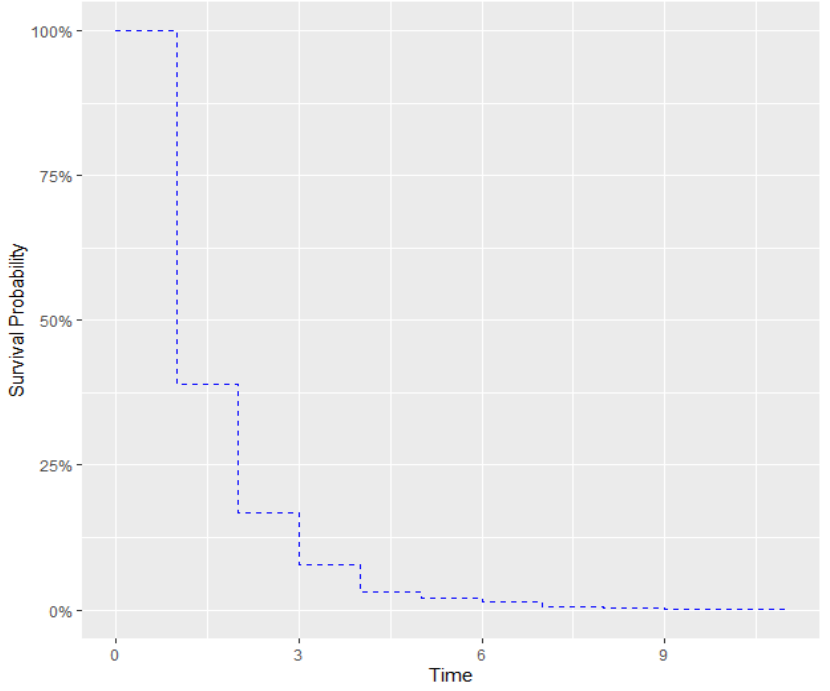

